\title{
Article \\ Sensitivity Analysis for Carbon Emissions of Prefabricated Residential Buildings with Window Design Elements
}

\author{
Simeng Li ${ }^{1}$, Yanqiu Cui ${ }^{1, *}$, Nerija Banaitiene ${ }^{2}\left(\mathbb{D}\right.$, Chunlu Liu $^{3, *}\left(\mathbb{C}\right.$ and Mark B. Luther ${ }^{3}(\mathbb{C}$ \\ 1 School of Architecture and Urban Planning, Shandong Jianzhu University, Jinan 250101, China; \\ b20180108@stu.sdjzu.edu.cn \\ 2 Department of Construction Management and Real Estate, Vilnius Gediminas Technical University, \\ 10223 Vilnius, Lithuania; nerija.banaitiene@vgtu.lt \\ 3 School of Architecture and Built Environment, Deakin University, Geelong, VIC 3220, Australia; \\ luther@deakin.edu.au \\ * Correspondence: cyq@sdjzu.edu.cn (Y.C.); chunlu@deakin.edu.au (C.L.)
}

Citation: Li, S.; Cui, Y.; Banaitienè, N.; Liu, C.; Luther, M.B. Sensitivity Analysis for Carbon Emissions of Prefabricated Residential Buildings with Window Design Elements. Energies 2021, 14, 6436. https:// doi.org/10.3390/en14196436

Academic Editor: Benedetto Nastasi

Received: 28 August 2021

Accepted: 5 October 2021

Published: 8 October 2021

Publisher's Note: MDPI stays neutral with regard to jurisdictional claims in published maps and institutional affiliations.

Copyright: (c) 2021 by the authors. Licensee MDPI, Basel, Switzerland. This article is an open access article distributed under the terms and conditions of the Creative Commons Attribution (CC BY) license (https:// creativecommons.org/licenses/by/ $4.0 /)$.
Abstract: Owing to the advantages of high construction efficiency, prefabricated residential buildings have been of increasing interest in recent years. Against the background of global heating, designing low-carbon facades for prefabricated residential buildings has become a focus. The main challenge for this research is in designing windows for prefabricated residential buildings that can lead to the best performance in carbon emissions. The purpose of this paper is to summarize window design advice for prefabricated residential building facades with low-carbon goals. This paper adopts the single control variable research method. Building energy consumption and carbon dioxide emissions under different conditions comprise the primary data used in the study. In the process of achieving the research aim, this study firstly extracts the window design elements of prefabricated residential facades. Secondly, objective function formulas are established and a basic model is built for obtaining data. Thirdly, data results are analyzed and window design advice is put forward under the condition of a low-carbon goal. This paper discusses that the optimal window-to-wall ratio (WWR) with a low-carbon orientation is around 0.15 , and compares it innovatively with the optimal WWR under an energy-saving orientation at around 0.38. The research results of this paper can deepen the understanding of architectural low-carbon design and play a guiding role for architects.

Keywords: carbon emissions; prefabricated residential building; sensitivity analysis; window design

\section{Introduction}

As an architectural component in contact with the outside world, building facades have a significant impact on indoor physical environments and energy consumption [1]. However, architects tend to pay more attention to the esthetic features of building facades, the "name card of buildings". They often ignore the need for carbon reduction when designing or changing facade design elements because of a lack of low-carbon and energysaving design methods. The exterior wall panels of prefabricated buildings have openings according to their window designs. They are prefabricated in factories and transported to construction sites for assembly. Window design is different from the design of other elements such as facade materials and construction equipment, which can be modified later. Window design cannot change after entering the production process for prefabricated residential wall panels and, as a result, problems cannot be addressed after the initial design stage. Industrialized production will magnify the early design problems and double the waste of building energy [2]. Research from the International Energy Agency shows that the initial planning and design stages of building schemes have huge potential for energy saving [3]. Therefore, it is necessary to set the goal of reducing carbon emissions in the initial stage of the design of facade windows for prefabricated houses. Furthermore, 
discussing design methods for exterior wall parts in relation to a low-carbon goal is of great significance in prefabricated residential buildings [4].

On the one hand, the carbon dioxide $\left(\mathrm{CO}_{2}\right)$ emissions of buildings are closely related to energy consumption [5]. It is necessary to understand whether this will lead to different design outcomes when taking various measurements, such as energy consumption or $\mathrm{CO}_{2}$ emission, and to discuss the similarities and differences between low-carbon design and energy-saving design. Although there is some research on window design optimization based on improvement in building performance [6], most studies aim to save energy and improve the indoor thermal environment [7]. There are few studies of window design optimization with a low-carbon goal [8]. On the other hand, building energy consumption and $\mathrm{CO}_{2}$ emissions in different climate zones vary with different window-to-wall ratios (WWRs) [9]. However, studies on low-carbon designs for windows in cold regions of China are still scarce. Therefore, this study takes Jinan, a city in Shandong Province in a cold region in China, as an example and prefabricated residential buildings as the research object. It is important to carry out a study of window design with a low-carbon goal. The research results can be applicable to buildings in cold regions of China.

Window size is closely related to the energy consumption of building heating, cooling, and lighting [10]. Previous studies have shown that an optimal WWR exists when using annual total energy consumption as a measurement index [11]. The optimal WWR can minimize total yearly energy consumption. There are three research questions addressed in this paper. Firstly, what is the difference between the impacts on the optimal WWR of a low-carbon target and of an energy-saving target? Secondly, how do window design elements affect the optimal WWR? Thirdly, what is the best window design for achieving a low-carbon goal in buildings? This research firstly establishes functional relationships between energy consumption, $\mathrm{CO}_{2}$ emissions, and the optimal WWR. Then, a basic model is selected and the variables of window design elements are explained based on the model. The window area, window shape, and window position are taken as the variables in carrying out parameterized changes. Each variable corresponds to one working condition. Then, data on energy consumption and $\mathrm{CO}_{2}$ emissions under different working conditions are obtained by computer simulation. The study analyzes these data to compare the optimal WWR values in relation to low-carbon and energy-saving goals, and explores the effect of each window design element on the optimal WWR. Finally, advice on the design of window elements is provided.

The purpose of this paper is, on the one hand, to help designers understand the differences between low-carbon design and energy-saving design. On the other hand, this research aims to summarize the influence of facade window design parameters on carbon emissions and to provide design advice for optimum window size, location, and shape in prefabricated residential buildings in relation to low-carbon goals. This paper will help in making correct design decisions for low-carbon window design and provide advice for architects on low-carbon window design for prefabricated residential buildings. All in all, in the initial stage of the facade design for prefabricated residential buildings, analyzing the effects of facade window design elements on energy consumption and carbon emissions is of great importance for energy conservation and carbon emission reduction [12].

\section{Window Design for Prefabricated Residential Buildings}

In this chapter, literature on residential window design is investigated. Based on literature research, elements and principles of window design of prefabricated residential buildings are summarized. It is a foundation for the research method in the next chapter.

\subsection{Literature Review on Residential Window Design}

As one of the components of residential facades, windows have many properties [13]. One class of properties influences architectural modeling, including formal properties, color properties, material properties [14], and so on. For example, the facades of kindergartens often use circular windows to show the lively character of these buildings. The 
colored windows of Gothic churches show the mystery of religious buildings [15], while modern public buildings usually use large windows and modern materials to reflect a sense of science and technology [16]. People can even judge the style and historical culture of buildings from the facade window designs. Based on the principles of formal esthetics, architectural designers express creative concepts using the properties and characteristics of windows. Besides the influence of various window properties on the esthetics of building facades, there is also a class of window properties that greatly influence building performance [17] and indoor environment quality [18]. For example, window size, materials, and shade components will impact building energy consumption and indoor lighting. Window opening modes, orientations, and positions will affect indoor airflow environments [19]. These aspects have attracted much attention by scholars.

This paper uses ScienceDirect as a database platform, using "window design performance" and "window to wall ratio" as keywords to search. There are nearly 112,636 search results since 2000. In the search results, articles related to the optimal WWR and from the beginning were selected, and then 20 representative articles were chosen. This paper analyzes the window properties mentioned in these articles that can affect building performance and indoor environments. As shown in Table 1, these papers cover all the properties of windows that can impact building performance: window area, glass material and structure, window position, window shape, whether the window has sunshade components, and window orientation. Each chosen paper has conducted research on some of these six aspects and discussed the influence of specific design elements on buildings' energy consumption or indoor environments.

Table 1. Types of window properties.

\begin{tabular}{cc}
\hline Window Property & Reference \\
\hline Area & {$[20-36]$} \\
\hline Glazing & {$[20,23,24,29,36-38]$} \\
\hline Position & {$[25,31,36,39,40]$} \\
\hline Shape & {$[21,22,31,36,39]$} \\
\hline Shading & {$[20,26-28]$} \\
\hline Orientation & {$[21-24,26-30,32,33,35,40]$} \\
\hline
\end{tabular}

In most of the articles in Table 1, changes in window size and orientation are involved. Most studies of window shade components are about linkages with different orientations [20]. The influence of window glass thickness and structure on building heating and cooling energy consumption has been studied [37]. In analyses of window position, most researchers have only controlled for simple movement of windows in the horizontal direction on a wall and the movement variable is not continuous. The influences of window shape and relative position on indoor airflow patterns have also been studied. As a research object, two windows were on two opposite walls of a suite [39].

The effects of window position and size on indoor airflows have been investigated by means of on-site measurement and computer simulation. There are only two variables for window position: one location in the center of a wall and the other on the left-hand side of a wall by horizontal movement. The study results showed that two non-adjacent openings had a better ventilation effect than two adjacent openings [25]. The influence of window position on energy consumption and lighting has been studied in some research [36]. There are only two types of window position: "centered" and "upper". Researchers have also studied the relationship between window shape and energy consumption, with window shape classified as square, horizontal rectangle, or vertical rectangle [31].

When taking window shape as an independent variable, its influence on the indoor airflow environment has been studied. Window shape was classified as horizontal rectangular, vertical rectangular, or square. Window area remained unchanged when changing window 
shape. The study concluded that, when the shapes of the air inlet and the air outlet are square, this is most beneficial to the indoor airflow [39]. However, some researchers have ignored the change in window shape when changing WWR. For example, a method for studying the optimal WWR for low-energy office buildings in temperate marine climates was provided in a study, where the window shape changed because it was not enlarged in equal proportions [33]. In addition, another study changed window shape while changing the value of WWR, but did not consider window shape a variable [32].

The most comfortable indoor ventilation mode and optimal WWR have been explored by taking facade window orientation, WWR, and shading properties as independent variables. The number of uncomfortable indoor temperature hours throughout the year was treated as the measurement index [26]. The WWRs of living rooms and bedrooms that were oriented in the same direction were changed in the paper, which explored several ventilation methods combining natural ventilation and mechanical ventilation. Finally, the relationship between the optimal WWR and ventilation method was assessed by taking energy consumption and indoor thermal environment comfort as measurement indexes [34].

The WWR is affected by many factors. Some articles have studied the influence of glass materials on WWR, including the solar heat gain coefficient (SHGC) and U-value of the glass [24]. Some articles have studied the influence of different orientations and different climates on WWR [23]. Each article picks out several factors to study the influence of these factors and the WWR. Other factors are set to fixed values because the controlled variable method is adopted. Among the window properties discussed above that can impact building performance, some such as window size, shape, position, material, and design of sunshade components have significant affects on the esthetics of building facades. Architects use windows as esthetic elements to express architectural creativity. However, architects are also responsible for improving the performance of a building when creating architectural products. Therefore, how to take into account both the esthetic features of window design and the improvement of building performance has become a complex problem. This requires architects to have the ability to predict the influences on building performance when adjusting window design elements. This is also one of the research goals of this paper: to summarize low-carbon design methods for prefabricated residential windows to provide a reference for architects in designing beautiful and low-carbon buildings.

\subsection{Elements and Principles of Window Design for Prefabricated Residential Buildings}

Unlike traditional cast-in-place residences, prefabricated residential buildings need to follow modular principles in the design stage to ensure their parts meet industrial requirements. The components of prefabricated residential buildings are prefabricated in factories. Construction can be completed quickly by assembling the components on construction sites. Prefabricated residential window parts are generally produced in the factory together with entire external wall panels. According to window design drawings, exterior wall panels need to incorporate window openings and then proceed to mass production on assembly lines after mold creation.

It has been shown that window size, shape, position, and sunshade component settings impact the esthetics of architectural design and the improvement of architectural performance. However, as the design and production of window sunshade components can be separated, their installation can be more flexible. However, in the integrated design of windows and exterior wall panels for prefabricated residential buildings, the size, shape, and position of windows are design elements that need to be determined first. Therefore, this paper defines window design elements as the size, shape, and position in the exterior wall panels of prefabricated residential buildings. Wall panels are changed through differences in these three window design elements. As shown in Figure 1, a prefabricated wall panel can be transformed into three different wall panel types by changing these window design elements. The original panel becomes wall panel 1 by changing the window area. Wall panel 2 and wall panel 3 come from the original panel by changing the window shape and position elements. It can be seen that, after such modular design, three 
different wall panels will create completely different building facades and have different effects on building performance.

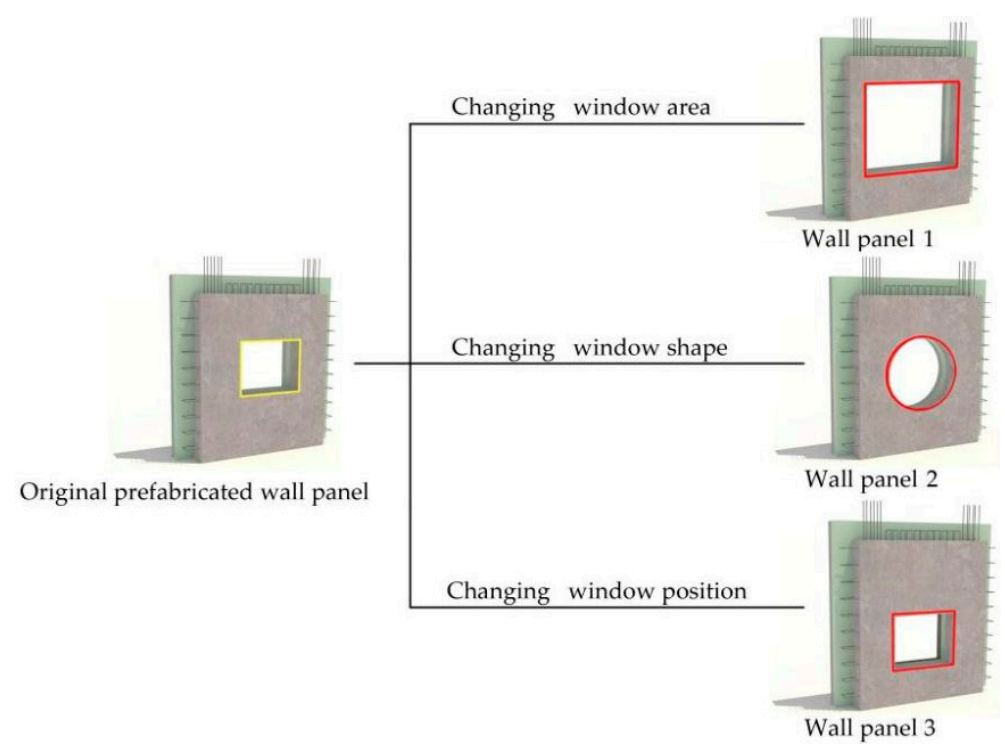

Figure 1. Schematic diagram of three prefabricated residential window design elements.

These three design elements of prefabricated residential windows are independent and can be changed individually or simultaneously. Generally, each design element has a corresponding measurement index to control its change. For example, the WWR measures the window area design element. It refers to the ratio of the window opening area to the wall area. The length-width ratio measures the shape of windows, such as which forms are rectangular. Previous research has often ignored the design factor of window shape.

Prefabricated residential buildings often leave people with a slightly boring impression of a facade owing to the mass use of standardized parts. For instance, such facades rarely use circular windows. Therefore, this paper studies rectangular windows of different proportions and takes circular windows as a research object that aims to increase the diversity of facade window design for prefabricated residential buildings. The distance between the window contour line and each edgeline of the exterior wall panel controls the window position element of prefabricated residential buildings. This involves five types: center, center to top, center to bottom, center to the left, and center to the right. In this study, the height of the lower edgeline of a window from the ground measures the window position.

Architects should adopt the following five principles in window design for prefabricated residential buildings. First of all, window design should meet functionality requirements. This means window designs should fit physical environment requirements like indoor lighting and ventilation, and provide a comfortable indoor environment for residents [41]. Secondly, prefabricated residential windows should follow the design principle of being low carbon and energy saving [42]. This principle plays a vital role in the face of today's energy shortages and environmental crisis. In order to comply with this principle, window design needs to select the appropriate size, U-value, and SHGC according to building codes. Thirdly, the design of prefabricated residential windows should follow the principles of standardization and modularization [43]. This means window components for prefabricated residential buildings should meet the needs of industrial production and efficient construction. Fourthly, the design of prefabricated residential windows should follow the principle of fewer specifications and more combinations [44]. This principle can better help prefabricated houses to achieve standardization and diversification. Fifthly, the design of prefabricated residential windows should follow the rules of form esthetics. As an important factor influencing the effect of the facade, the design of windows should 
follow formal esthetic principles such as unity and change, balance and stability, symmetry and rhythm, harmony and contrast, and proportion and scale [45].

The design of prefabricated residential window parts is in an upstream position in the overall industrial chain. They cannot be changed once completed. Defects in traditional cast-in-place residential window design will only cause adverse effects in specific projects. In contrast, design defects in prefabricated residential window parts will be magnified by large-scale industrial production. In order to achieve a low-carbon target for prefabricated residential buildings, this paper researches the influence of window design elements on energy consumption and $\mathrm{CO}_{2}$ emissions, then discusses low-carbon design advice for window elements. The research methodology is introduced below.

\section{Research Methodology}

Analyzing the influence of window design elements on energy consumption is helpful to build a theoretical foundation for the objective function. The construction of the objective function provides a method to obtain the optimal WWR. The design of calculation schemes clarifies the change path of window design elements. In addition, the energy consumption and $\mathrm{CO}_{2}$ emission data used in this research were obtained from the simulation software. The research problems can be solved by processing and analyzing the data. Each part will be introduced in detail next.

\subsection{Influence of Window Design Elements on Energy Consumption}

To study the relationship between window design elements and energy-saving or low-carbon goals, firstly, it is necessary to clarify which types of energy consumption will be affected by window design elements and to understand the background theories. Ordinarily, the energy consumption of buildings consists of many parts. From a macro perspective, building energy consumption includes all kinds of energy consumption in the entire process from material production to construction, operation, maintenance, demolition, and recycling. In this paper, the scope of building energy consumption is energy consumption during a building's operation phase. During this phase, energy consumption is also composed of many subtypes including heating energy consumption, cooling energy consumption, lighting energy consumption, household electrical equipment energy consumption, and so on. Therefore, it is necessary to first analyze the subtypes of energy consumption related to the window design elements.

The facade is a medium of energy exchange between the interior and exterior of a building. When the energy transfer between indoor and outdoor environments reaches a balance, the indoor temperature also reaches a stable state. The energy consumption of heating and cooling is generated in this process. As shown in Figure 2, the principles of heating and cooling energy consumption generated in winter and summer, respectively, were analyzed. The pattern of energy exchange of the building facade is the same in both seasons. The surfaces of building facades that are in contact with outdoor space mainly exchange energy through solar radiation, environmental radiation, and air convection, while the surfaces of building facades that are in contact with indoor space mainly exchange energy through indoor interface radiation, indoor energy radiation, and indoor air convection.

Owing to the difference between the outdoor temperature $T_{0}$ and the indoor temperature $T_{1}$, there is a temperature difference between the outer surfaces and inner surfaces of the building envelope. The temperature difference between $T_{0}$ and $T_{1}$ causes heat conduction. In winter, as shown in Figure $2 a$, the outdoor temperature $T_{0}$ is less than $T_{1}$ and the heat lost through the wall is more than the heat gained. Therefore, to maintain a comfortable indoor temperature, it is necessary to use heating to make up for the energy gap. As a result, heating energy consumption $\mathrm{E}_{\mathrm{H}}$ is generated. In summer, as shown in Figure $2 b$, the outdoor temperature $T_{0}$ is greater than $T_{1}$ and the heat obtained through the wall is greater than the heat lost. In order to maintain a comfortable indoor temperature, 
it is necessary to use cooling to take away the excess heat. Therefore, cooling energy consumption $\mathrm{E}_{\mathrm{C}}$ is generated.

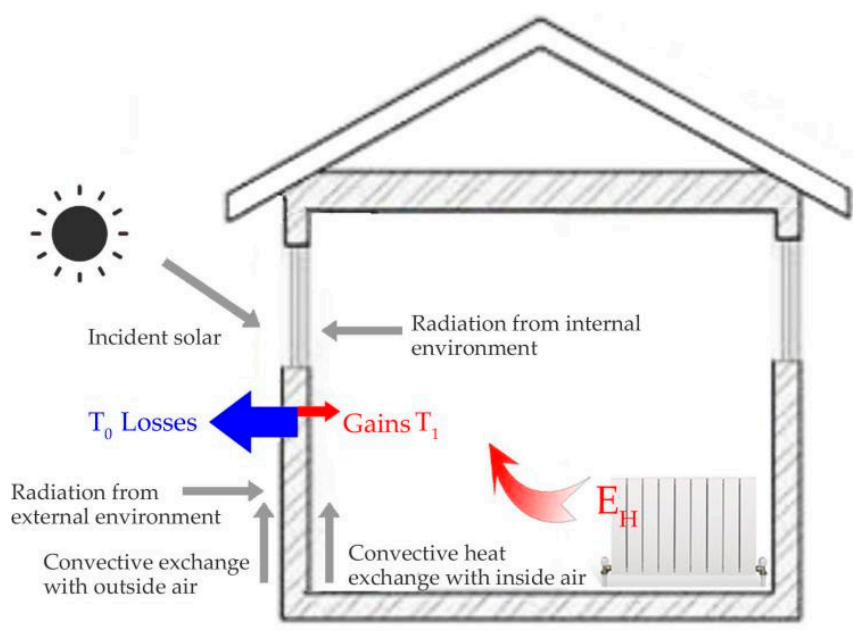

(a) Winter

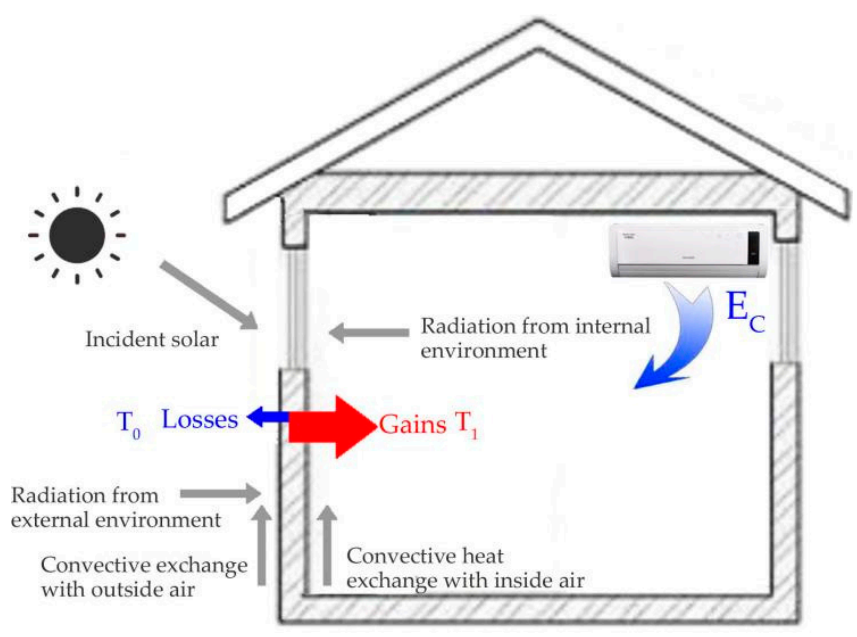

(b) Summer

Figure 2. Heat transfer analysis of building facades in (a) winter and (b) summer.

The ability of building facades to gain and dissipate heat plays a vital role in building energy consumption [46]. The ability of building facades to obtain energy mainly depends on the absorption and transmission of solar radiation flux and thermal conductivity, while their ability to dissipate heat depends primarily on the thermal insulation of their facades. The ability of external facades to obtain and dissipate heat determines the thermal balance performance of the facades. The thermal balance plays an essential role in maintaining the indoor temperature and has a vital impact on the energy consumption of buildings. For example, building facades with good heat-shielding performance in summer can help buildings reduce the energy obtained from the outside environment. As a result, it helps to reduce buildings' cooling energy consumption $\mathrm{E}_{\mathrm{c}}$. In winter, building facades with good thermal insulation properties can reduce the heat lost through facades, thus helping to reduce heating energy consumption $\mathrm{E}_{\mathrm{H}}$.

Generally, walls have good thermal insulation performance and low light transmittance, both of which are beneficial for building insolation [47]. However, window glass has poor heat insulation and high light transmittance, which are good for getting heat from outside in winter, but bad for heat-shielding in summer [48]. Therefore, a change in the WWR will significantly affect the thermal balance performance of building facades [32], thereby affecting the heating energy consumption $\mathrm{E}_{\mathrm{H}}$ and cooling energy consumption $\mathrm{E}_{\mathrm{C}}$ of buildings. Simulation software calculates heating and cooling energy consumption using heat balance theories like this. Therefore, among the window design elements, the area of windows is closely related to the building heating energy consumption $\mathrm{E}_{\mathrm{H}}$ and cooling energy consumption $\mathrm{E}_{\mathrm{C}}$.

In order to ensure that residents can carry out everyday living activities in the interior of residences, it is necessary to open windows to let natural lighting come into buildings [49]. Under the same external lighting conditions, the size, shape, and position of windows will significantly impact the amount of lighting and the uniformity of illumination. Generally speaking, a room will get a greater amount of illumination with larger windows. Vertical rectangular windows have good lighting uniformity in the depth direction of rooms, while horizontal rectangular windows have good lighting uniformity in the width direction of rooms and the height of windows will affect the uniformity of lighting in the depth direction of rooms [50]. The illumination and uniformity of indoor natural lighting have significant impacts on lighting energy consumption. When the level of illumination of natural lighting fails to meet requirements on work surfaces, people will 
use artificial lighting and generate lighting energy consumption $E_{L}$. Therefore, lighting energy consumption $\mathrm{E}_{\mathrm{L}}$ is also closely related to window design elements.

According to the above discussion, the subtypes of energy consumption related to window design elements in a building's operation phase mainly include heating energy consumption $\mathrm{E}_{\mathrm{H}}$, cooling energy consumption $\mathrm{E}_{\mathrm{C}}$, and lighting energy consumption $\mathrm{E}_{\mathrm{L}}$. The design element of window area primarily affects the heating energy consumption $E_{H}$ and cooling energy consumption $\mathrm{E}_{\mathrm{c}}$. The design elements of window shape and position mainly affect the lighting energy consumption $E_{L}$ of a building. The discussion above is a theoretical foundation for constructing objective functions to analyze the influence of the window elements on energy consumption and WWR. A further detailed sensitivity analysis of the impacts of the window design elements on the optimal WWR is given in Section 4.2.

\subsection{Objective Functions and Optimal WWR}

Saving energy and reducing carbon emissions are the two design goals addressed in this paper. It is first necessary to determine how to obtain the value of the optimal WWR if we want to compare the results for the optimal WWR according to different objective orientations. Therefore, the objective function and the concept of optimal WWR need to be established first.

In this research, only energy consumption related to window design is studied; as a result, energy consumption generated by household appliances, among others, is not included in the consideration. Building energy consumption related to window design elements in the building operation phase comprises three subtypes: heating energy consumption, cooling energy consumption, and annual lighting energy consumption. The measurement unit of energy consumption is years. Therefore, energy consumption as studied in this paper refers to the annual heating energy consumption $\mathrm{E}_{\mathrm{H}}$, annual cooling energy consumption $E_{C}$, annual lighting energy consumption $E_{L}$, and total annual energy consumption $\mathrm{E}_{\mathrm{TO}}$. This paper first takes energy consumption as a measurement index and establishes an objective function as shown in Formula (1).

$$
\mathrm{E}_{\mathrm{TOT}}=\mathrm{E}_{\mathrm{H}}+\mathrm{E}_{\mathrm{C}}+\mathrm{E}_{\mathrm{L}}
$$

The greenhouse gas produced during the operation phase of buildings is mainly $\mathrm{CO}_{2}$, and the calculation result is usually measured in $\mathrm{kgCO}_{2}$. This paper uses $\mathrm{kgCO}_{2}$ as the measurement unit. The equivalent $\mathrm{CO}_{2}$ of different greenhouse gases is not considered. The $\mathrm{CO}_{2}$ emissions generated during the building operation phase are calculated by multiplying the energy consumption by the $\mathrm{CO}_{2}$ emission coefficient. Therefore, an objective function is established in relation to the low-carbon goal, as shown in Formula (2). The annual value of $\mathrm{CO}_{2}$ emissions $\mathrm{C}_{\mathrm{TOT}}$ is the annual heating energy consumption $\mathrm{E}_{\mathrm{H}}$ multiplied by the $\mathrm{CO}_{2}$ emission coefficient of heating energy $\mathrm{f}_{c}$, plus the value of the electricity $\mathrm{CO}_{2}$ emissions coefficient $\mathrm{f}_{\mathrm{E}}$ multiplied by the sum of the cooling energy consumption $\mathrm{E}_{\mathrm{C}}$ and the lighting energy consumption $\mathrm{E}_{\mathrm{L}}$.

$$
\mathrm{C}_{\mathrm{TOT}}=\mathrm{f}_{\mathrm{C}} \mathrm{E}_{\mathrm{H}}+\mathrm{f}_{\mathrm{E}}\left(\mathrm{E}_{\mathrm{C}}+\mathrm{E}_{\mathrm{L}}\right)
$$

The two energy-saving and low-carbon target orientations correspond to two measurement indicators: energy consumption and $\mathrm{CO}_{2}$ emissions. When energy consumption is taken as an indicator, the concept of the optimal WWR is the value of the corresponding WWR when the total annual energy consumption reaches a minimum. In the same way, when the annual $\mathrm{CO}_{2}$ emissions are taken as an indicator, the concept of the optimal WWR is the value of WWR corresponding to the minimum yearly $\mathrm{CO}_{2}$ emissions.

Compared with the objective function for energy consumption, the objective function for carbon emissions will alter the function curve's change rate and the value of the optimal WWR because each component of the function is multiplied by a coefficient. The concept of 
the optimal WWR lays the foundation for addressing the three research problems proposed in this paper.

\subsection{Calculation Schemes}

Selecting a typical residence as a basic model is necessary for the research. The results obtained from a basic model can be used as a reference for other similar cases. This section will give a detailed introduction to the basic model selection and variable design schemes of window elements.

\subsubsection{Basic Model Information}

The process of building a basic model for prefabricated residential buildings can be divided into three steps. Firstly, select a plane model. Secondly, determine the height of each floor based on modularization. Thirdly, choose structural types and thermal parameters for the building facade. After these three steps, a basic model has been established.

The plane for prefabricated residential buildings needs to meet the requirements of modularization and standardization. In order to choose a representative residential plane that meets these requirements, this study conducts investigations and analyzes statistics in the "Standard Atlas Design of Prefabricated Residential Buildings in Shandong Province" L16J901. There are 170 cases in the atlas. The compilation of this atlas is based on analyses of household needs and surveys of the current prefabricated residential design in Shandong Province. The purpose of investigating this atlas is to provide architects with a reference when designing prefabricated residential buildings. In the future, the residential building cases in this atlas can be applied in many prefabricated residential construction practices. Thus, the residential building cases in this atlas are very representative and practical.

The width and depth of 170 residential building cases were counted and the data are shown in Figure 3. Through data analysis, it can be concluded that the width of these prefabricated houses is concentrated in the range of 5-7 $\mathrm{m}$. The depth of these prefabricated houses is concentrated in the range of 8-10 $\mathrm{m}$, which means that there are more prefabricated residential buildings in this size range. The basic model selected from this size range will be more representative.
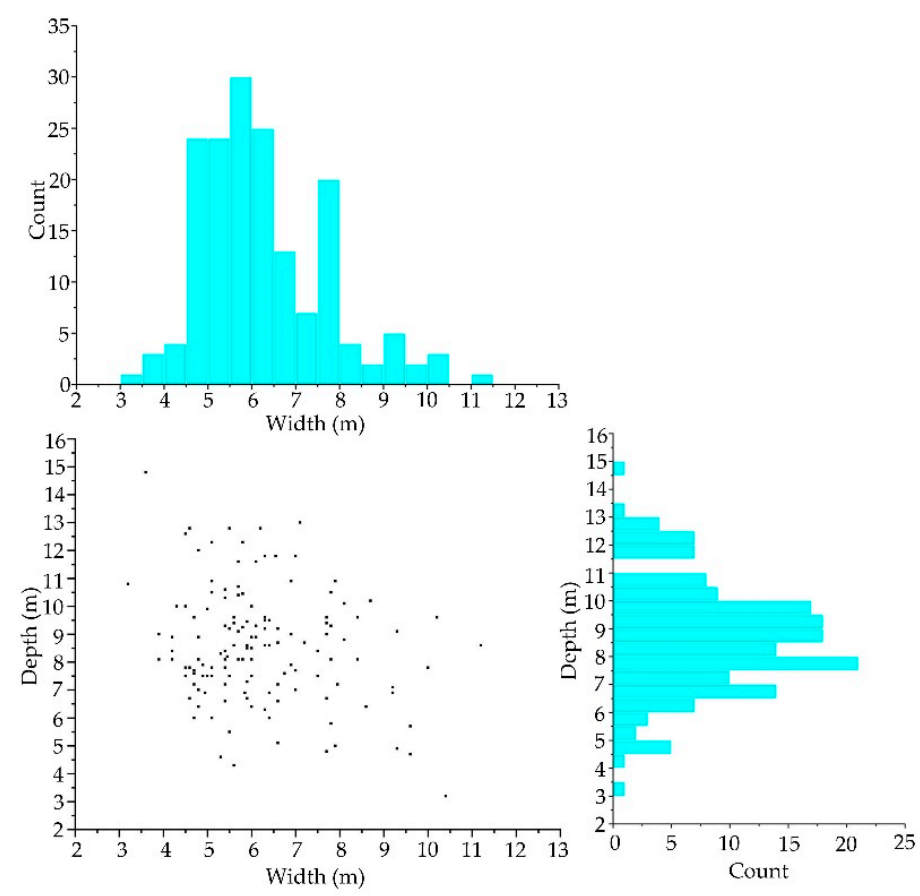

Figure 3. Statistics on width and depth of cases in the atlas. 
Therefore, the case shown in Figure 4 was selected from the atlas as a basic model. Its width and depth are in the concentrated range discussed above. The width of the basic model is $6 \mathrm{~m}$, its depth is $8.1 \mathrm{~m}$, and the building area is $48.6 \mathrm{~m}^{2}$. The plan is a common type in China. In addition, the floor height of prefabricated residential buildings is generally 2800-3300 mm. According to the "Guiding Standards for Floor Height of Prefabricated Residential Buildings" issued by the Jinan Urban and Rural Construction Committee, the floor height should be $2900 \mathrm{~mm}$. This standard serves as a principle for the design of the floor height of prefabricated residential buildings in Jinan. Therefore, the floor height of the basic model in this study is determined to be $2900 \mathrm{~mm}$.

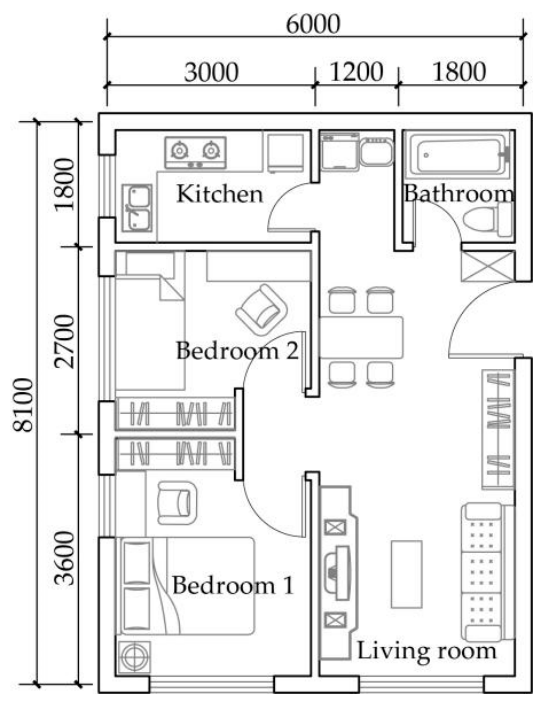

Figure 4. Floor plan design of the basic model (unit: $\mathrm{mm}$ ).

As mentioned in Section 2.1, the WWR is affected by many factors, such as glass material, orientation, and climate. This article adopts the single control variable research method. Therefore, the other influencing factors of the building model remain unchanged when studying the influence of the prefabricated residential window design elements on WWR. In this study, the orientation of the model remains unchanged. The basic model uses an autoclaved lightweight concrete panel. In Appendix A, Table A1 gives the thickness and thermal parameters of the wall panel from outside to inside. The heat transfer coefficient of the wall panel is calculated to be $0.361\left(\mathrm{~W} / \mathrm{m}^{2} \cdot \mathrm{K}\right)$. In addition, the window is made of plastic profile double-glazed hollow glass. Table A2 gives the optical and thermal performance parameters of the window. Table A3 gives the structural and thermal parameters of other parts of the basic model. The thermal parameters of each part of the envelope meet the requirements of the "Technical Standards for Near-Zero Energy Buildings" GB/T 51350-2019.

The basic model's plane size, facade size, facade structure, and thermal parameters directly impact energy consumption and $\mathrm{CO}_{2}$ emissions. This is the basis for understanding and analyzing the research results. Energy consumption may be different for different cases, but this will not influence the results because models are a constant factor in the horizontal comparison of research variables, and thus this will not impact the final research conclusion.

\subsubsection{Window Design Element Variables}

In order to discover the influence of the different window design elements on the optimal WWR, it is necessary to determine the different conditions of the basic model according to the change in window design elements and then calculate the values for energy consumption and $\mathrm{CO}_{2}$ emissions under each condition. Therefore, the following describes the design of the variable calculation schemes for the different design elements. 
The window design elements mainly consist of window size, position, and shape. As a variable index, the WWR controls the size of windows. There are ten values of the WWR, as shown in Figure 5, and the step of change is 0.1. In some conditions when the WWR cannot reach the maximum value of 0.7 , the maximum value can be set to 0.65 or 0.67 to cover a wider range of calculated data.

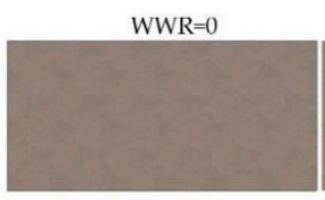

WWR $=0.5$

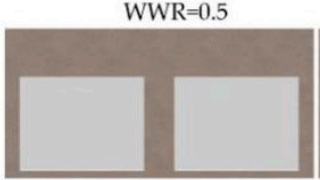

$W W R=0.1$

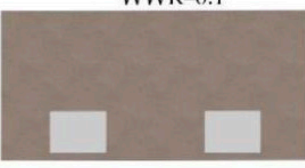

WWR $=0.6$

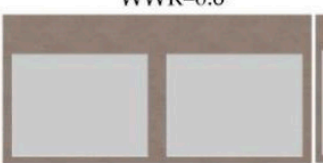

$W W R=0.2$

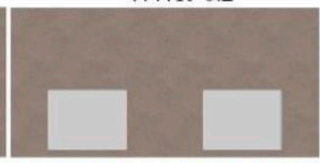

WWR $=0.65$

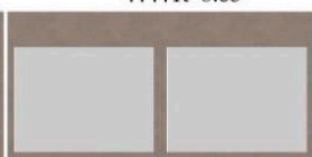

$\mathrm{WWR}=0.3$

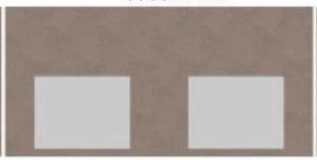

$\mathrm{WWR}=0.67$

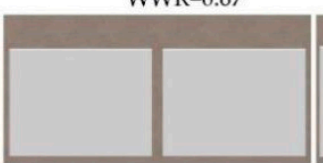

$\mathrm{WWR}=0.4$

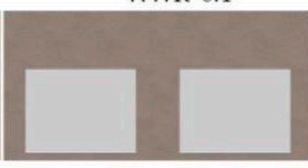

WWR $=0.7$

Figure 5. The 10 changing values of the WWR.

This paper adopts the single control variable research method and divides the calculation into two groups according to window shape and position. Group one is the window shape calculations, which only changes window shapes and areas according to the parameter value table. The height of a window from the ground remains unchanged at $150 \mathrm{~mm}$. The shape of windows in group one has two types, which are rectangular and circular. According to the different shapes of windows, there are four working conditions. The variable of aspect ratio $\mathrm{a} / \mathrm{b}$ controls the shape of rectangles, divided into a square with an aspect ratio of 1:1, a vertical rectangle with an aspect ratio of 3:4, and a horizontal rectangle with an aspect ratio of 4:3. Table 2 shows the changes in each window shape and the corresponding WWR.

Table 2. Window shapes and corresponding WWRs.

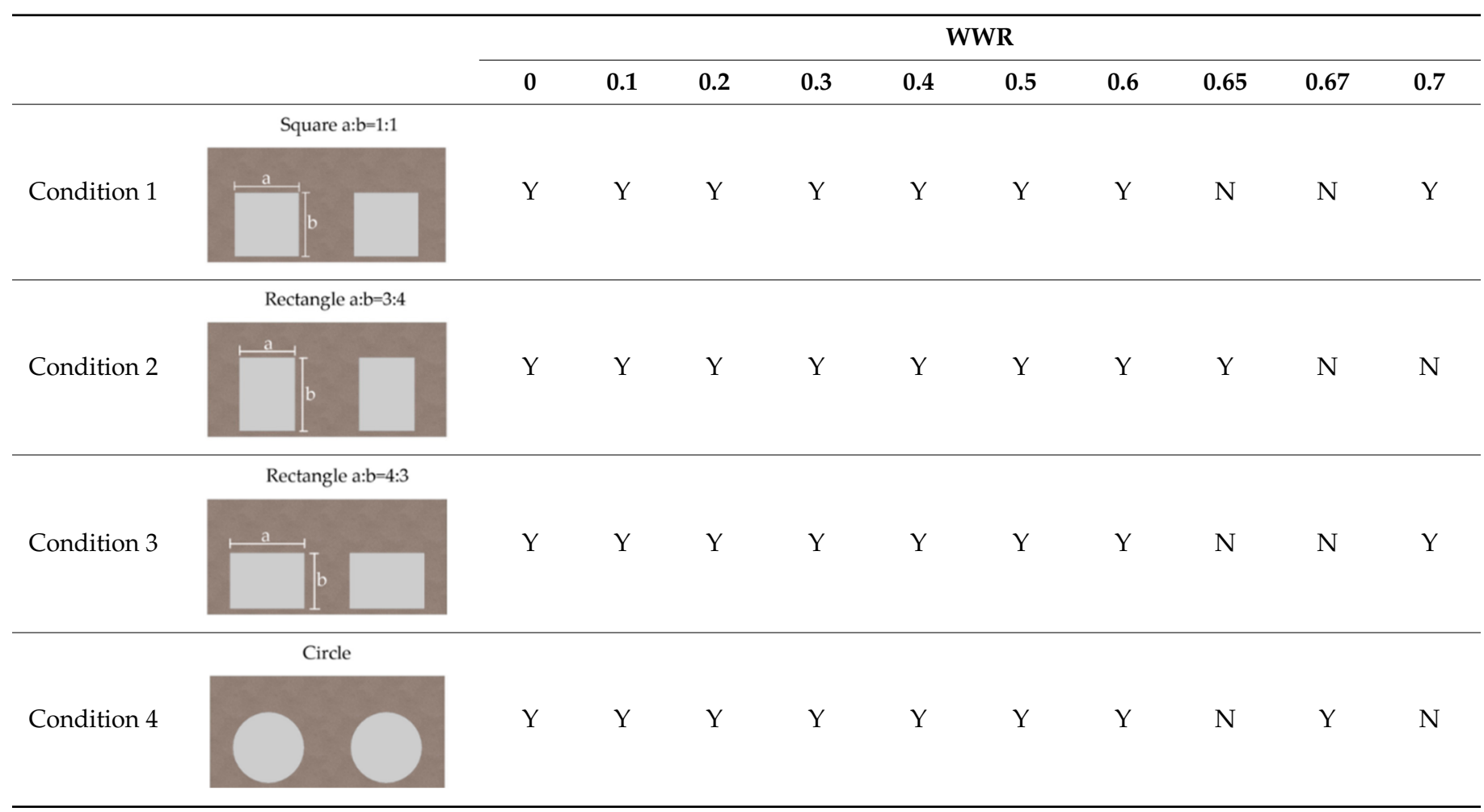


The second group is the calculations of the window position elements. Table 3 shows the position and corresponding WWR of each window. Only window positions and areas are changed, while window shapes keep the aspect ratio unchanged at 4:3. As shown in Table 3, window positions are parameterized by the height " $\mathrm{h}$ ", which means the height from the bottom edge of a window to the ground.

Table 3. Height " $h$ " from the bottom edge of a window to the ground and corresponding WWRs.

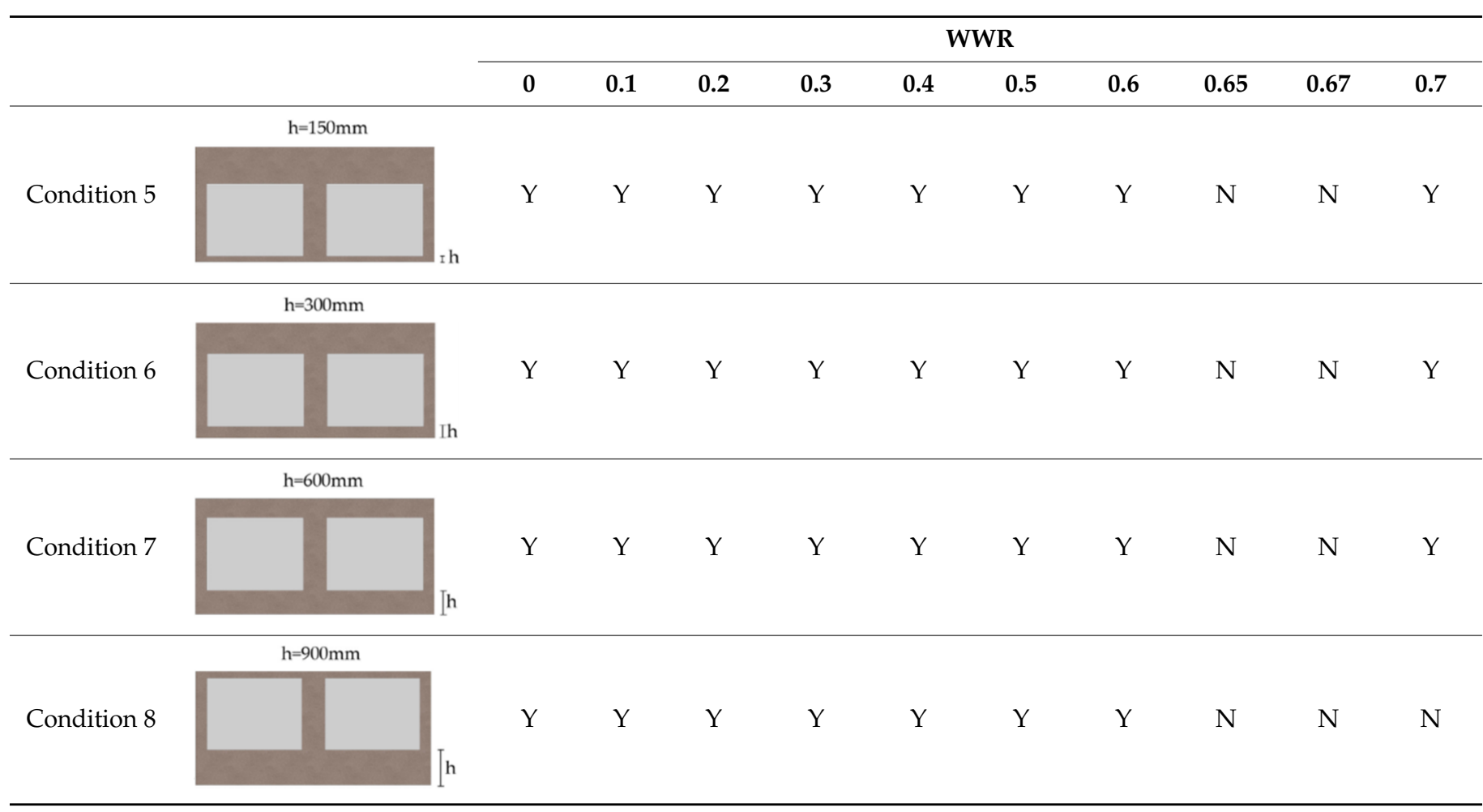

"Y": including the value of WWR. "N": not including the value of WWR.

There are four variables for position elements, all of which meet modularization requirements: $150 \mathrm{~mm}, 300 \mathrm{~mm}, 600 \mathrm{~mm}$, and $900 \mathrm{~mm}$. The calculation scheme shown in Tables 2 and 3 contains 8 working conditions and 128 calculations under the two targets: energy consumption and $\mathrm{CO}_{2}$ emissions.

\subsection{Simulation Parameter Setting and Result Analysis}

This paper uses DesignBuilder (DB) software as a calculation tool to obtain data on energy consumption and $\mathrm{CO}_{2}$ emissions [51]. This section will introduce the parameter setting of simulation software and explain the analysis method of the simulation results.

\subsubsection{Simulation Parameter Setting}

This research uses DB software to simulate energy consumption and $\mathrm{CO}_{2}$ emissions during the building operation phase. The data-acquisition process of the simulation software has two parts: model building and parameter setting. Model building is only necessary to establish a $3 \mathrm{D}$ visual model consistent with the basic model information according to the size, material, and construction information described in Section 3.3.1. Parameter setting controls the building environment and usage, including geographical location, meteorological data setting, indoor thermal environment parameter setting, power setting when using equipment, $\mathrm{CO}_{2}$ emission coefficient setting, and so on. Indicators of these parameters influence the energy consumption and the comfort of the indoor environment. The indicators are selected according to building codes in China, which meet the needs of living. The following is mainly about the simulation parameter setting. 
After establishing a model in DB according to the basic model information, the geographical location of the model was set to Jinan in the Shandong Province of China. Jinan belongs to a cold region. The meteorological data information used in the simulation is from DB. When setting the indoor thermal environment, as shown in Table 4, the upper limit of the air-conditioning temperature control in summer was $28^{\circ} \mathrm{C}$ and the lower limit was $26^{\circ} \mathrm{C}$. In winter, the lower limit of the heating temperature control was $18{ }^{\circ} \mathrm{C}$ and the upper limit was $24^{\circ} \mathrm{C}$. Temperature fluctuations in the room and switches in heating and cooling were according to the indoor temperature setting in the simulation software. That has an important impact on heating and cooling energy consumption. In addition, the indoor illuminance was set to 300 lux. The lighting power density was set to $6 \mathrm{~W} / \mathrm{m}^{2}$ according to the "Technical standard for nearly zero energy buildings" GB/T 51350-2019. Artificial lighting would be turned on when the illuminance did not meet this lighting requirement. The ventilation rate of the room is $0.5 \mathrm{~h}^{-1}$. In order to simplify the simulation, the other thermal comfort indicators are not considered in this paper. This is because the thermal comfort indicators are constant factors in the horizontal comparison of different cases, and thus this will not impact advice given for window design in some aspects.

Table 4. Model simulation parameter settings.

\begin{tabular}{cc}
\hline $\begin{array}{c}\text { Temperature } \\
\text { Setting }\end{array}$ & Winter: $18-24^{\circ} \mathrm{C}$ \\
\cline { 2 - 2 } Ventilation Rate & Summer: $26-28^{\circ} \mathrm{C}$ \\
\hline Indoor Illuminance Setting & $0.5 \mathrm{~h}^{-1}$ \\
\hline Lighting Power Density $\left(\mathbf{W} / \mathbf{m}^{\mathbf{2}}\right)$ & 300 \\
\hline Device Power Density $\left(\mathbf{W} / \mathbf{m}^{\mathbf{2}}\right)$ & 6 \\
\hline Plug and Process $\left(\mathbf{W} / \mathbf{m}^{\mathbf{2}}\right)$ & Living room 5/Bedroom 6/Dinning room \\
\hline Occupancy Density & 15 \\
\hline
\end{tabular}

Table 4 shows the parameters specified in the simulation. The heating schedule lasted all day because the cold regions of China use central heating. Furthermore, the energy for central heating mainly comes from coal combustion, while cooling and lighting primarily consume electric power. Therefore, the $\mathrm{CO}_{2}$ emission coefficient corresponding to heating energy consumption in this study is calculated according to the $\mathrm{CO}_{2}$ emissions coefficient of coal. The $\mathrm{CO}_{2}$ emission coefficient corresponding to the cooling and lighting is calculated according to the emission coefficient of electricity. The emission factor of $\mathrm{CO}_{2}$ per unit calorific value of coal is $89 \mathrm{~g} / \mathrm{MJ}$. Jinan belongs to the north China region and the average $\mathrm{CO}_{2}$ emission factor for this region is $245.639 \mathrm{~g} / \mathrm{MJ}$. The $\mathrm{CO}_{2}$ emission coefficients corresponding to the two energy sources were input into the simulation software to obtain the $\mathrm{CO}_{2}$ emission values during the building operation phase. The simulation period of the model is from January 1 to December 31 and the accuracy is calculated in the unit of hours, with a total of 8760 simulated hours.

\subsubsection{Data Processing and Analysis}

After simulation with the software, data on subtypes of energy consumption, total energy consumption, and $\mathrm{CO}_{2}$ emissions under different working conditions were obtained. As described in Section 3.3.2, data on the objective functions corresponding to the eight different values of WWR were obtained for each condition. Data on the objective functions include eight values for total energy consumption and 8 values for $\mathrm{CO}_{2}$ emissions. They also contain 24 subtype energy consumption values: 8 heating energy consumption values, 8 cooling energy consumption values, and 8 lighting energy consumption values. Expressing the data along axes for analysis, the X-axis represents the WWR and the $\mathrm{Y}$-axis represents energy consumption or $\mathrm{CO}_{2}$ emissions. A single point in the coordinate system 
represents the energy consumption or $\mathrm{CO}_{2}$ emission values for each WWR. In order to intuitively reflect the changing trends of the objective function curves for sensitivity analysis, the simulation results needed to be further processed. Each objective function was defined by eight discontinuous points in the coordinate system. The X-axis represents the WWR and the Y-axis represents energy consumption or $\mathrm{CO}_{2}$ emissions. Then, a suitable mathematical model to perform function fitting for the discontinuous data was selected. For each building, a fitting function was obtained. The function curve was drawn in the coordinate system. Then, by observing the function curve's change rules, the optimal WWR could be found and the effects of the window elements on the objective functions could be analyzed. It is important to emphasize that the data on optimal WWR points found in the research were not simulated, but found through the continuous curve drawn by the fitting function. Selecting more simulations would increase calculation and data processing time, but have little effect on the objective function curve. The reason for choosing eight data points to limit the number of simulations was that these eight data points cover the representative points of the WWR in the range $0-0.7$ and the number of calculations was the lowest.

The sensitivity analysis of simulation results was mainly carried out as follows. Firstly, the influence of the window design elements on heating energy consumption, cooling energy consumption, and lighting energy consumption under different window conditions was analyzed. Because the objective function is composed of these components, analyzing the subtype energy consumption helps in understanding the generation of optimal WWR results and in examining the impact of the window design elements on energy consumption and $\mathrm{CO}_{2}$ emissions. Secondly, the influence of the window design elements on the optimal WWR in addressing one of the research problems was analyzed. Comparing the optimal WWR under different window conditions helps in finding the influence of the window design elements on the optimal WWR. Meanwhile, the influence of window position and shape design elements on energy consumption and $\mathrm{CO}_{2}$ emissions can be revealed by varying window conditions with a fixed WWR. Thirdly, the influence of the different objective orientations on the optimal WWR was analyzed. Each window condition can generate two optimal WWR values in relation to the two objectives.

Through sensitivity analysis, we can discover which optimal WWR value is larger under the two different targets. At the same time, it was possible to analyze the similar and different influences of the other window design elements on low-carbon design and energysaving design when the value of the WWR was fixed. To analyze each factor's potential to reduce $\mathrm{CO}_{2}$ emissions, two working conditions are selected in each group of simulations. One is the most favorable working condition for reducing $\mathrm{CO}_{2}$ emissions and the other is the most unfavorable condition for reducing $\mathrm{CO}_{2}$ emissions. The corresponding $\mathrm{CO}_{2}$ emissions are expressed as Emin and Emax. Carbon reduction potential $=($ Emax - Emin $) / E m a x$, which indicates the highest possible rate of reducing $\mathrm{CO}_{2}$ emissions when optimizing the design factor.

Based on the above sensitivity analysis method, firstly, it is possible to propose design advice on window element design to reduce carbon emissions. Secondly, by analyzing the effects of different goal orientations on the optimal WWR, the differences between low-carbon window design and energy-saving window design can be summarized. This will help to provide specific low-carbon design guidance for windows of prefabricated residential buildings. The next chapter will provide a detailed analysis according to the method proposed in this section.

\section{Results}

The simulated data obtained under different window situations are analyzed in this chapter. The influence of window design elements on energy consumption or $\mathrm{CO}_{2}$ emission is discussed. Furthermore, low-carbon design advice for prefabricated residential windows is proposed. 


\subsection{Influence of Window Design Elements on Subtype Energy Consumption}

The objective function in this paper is composed of three factors with energy saving at the goal of design. These three factors are heating energy consumption $\mathrm{E}_{\mathrm{H}}$, cooling energy consumption $\mathrm{E}_{\mathrm{C}}$, and lighting energy consumption $\mathrm{E}_{\mathrm{L}}$. The objective function is also closely related to the three factors when taking $\mathrm{CO}_{2}$ reduction as the goal. The different window design elements have different impacts on subtype energy consumption. Therefore, it is necessary to first analyze the impact of the window design elements on subtype energy consumption, which is the basis for further sensitivity analysis. After the objective function was established, simulation software was used to calculate the subtype energy consumption contained in the objective function under different working conditions. The value of the WWR and corresponding energy consumption can be represented by a data point in a coordinate system. Then, the function-fitting method was used to process the data points and draw the obtained function curve in the coordinate system.

Figure 6 shows graphs for the energy consumption of each subtype changing with the WWR by fitting the data points of the subtype energy consumption obtained under the various working conditions. There are four curves in each figure, representing the four different window forms, respectively. However, as the data points for heating energy consumption and cooling energy consumption are very close when changing window shape, the phenomenon of occlusion between curves occurs in Figure $6 a, b, d$. In Figure $6 a, d$, there are almost two curves: the curves for the circular window and the curves for the square window almost overlap. In Figure $6 \mathrm{~b}$, only the difference in cooling energy consumption between the circular window and the square window can be distinguished. It can be seen from Figure 6a,b that, when the window area is the same, the circular window has the highest heating energy consumption and the lowest cooling energy consumption. The other three window shapes have little influence on heating energy consumption and cooling energy consumption, and mainly impact lighting energy consumption.

As shown in Figure 6c, the rectangular 3:4 window is the most favorable for reducing lighting energy consumption, while the rectangular 4:3 window is the most unfavorable for reducing lighting energy consumption. This is because the shape of the window impacts the lighting intensity and the uniformity of indoor natural light. The vertical rectangular window is more favorable to light in the depth direction of a room, and thus helps reduce the lighting energy consumption. Under each window condition, the overall trend of subtype energy consumption with an increase in WWR is as follows: heating energy consumption $\mathrm{E}_{\mathrm{H}}$ decreases, while cooling energy consumption $\mathrm{E}_{\mathrm{C}}$ and lighting energy consumption $E_{L}$ increase. Because of this opposing trend, the total energy consumption decreases first and then increases, so that the optimal WWR value appears. In addition, when the design goal is carbon reduction, as both cooling and lighting consume electricity, they are considered together. Therefore, to further explain the emergence of the optimal $W W R$ value and the influence of the different goal orientations on the optimal WWR, $\mathrm{E}_{C}$ and $\mathrm{E}_{\mathrm{L}}$ under various working conditions are taken together. The heating energy consumption curve $\mathrm{E}_{\mathrm{H}}$ is expressed in the same coordinate system, as shown in Figure 6d. Heating energy consumption $E_{H}$ uses coal as an energy source, while cooling and lighting energy consumption $E_{C}+E_{L}$ uses electricity as an energy source. As can be seen from the figure, the falling speed of $E_{H}$ gradually slows down with an increase in WWR, while the rising speed of $E_{C}+E_{L}$ changes from slow to faster with an increase in WWR. When the decreased value of $E_{H}$ is greater than the increased value of $E_{H}$, the total energy consumption shows a downward trend, while, with the reverse, the total energy consumption will increase.

Figure 7 shows the energy consumption as a function of the WWR with various window positions. In each part of the figure, there should be four curves representing the four different positions of the window. However, as the data points obtained under the different working conditions are very close to each other, the curves for the four working conditions in Figure $7 \mathrm{~b}, \mathrm{~d}$ almost overlap. As can be seen from Figure $7 \mathrm{~b}$, the height of the window from the ground has almost no effect on the cooling energy consumption. The curves in Figure 7a are also very close to each other. The WWR curves in Figure 7a 
within the range of $0.2-0.3$ are partially enlarged to enable distinguishing of the differences in heating energy consumption under the different window conditions. The details are provided in Figure 7a. As can be seen from the figure, when the window areas are the same, the heating energy consumption of windows higher from the ground is slightly greater than that of windows lower to the ground. However, the height of windows from the ground greatly impacts the lighting energy consumption. Windows with a higher position from the ground have lower lighting energy consumption. When the value of the WWR is less than 0.1, the higher the window is from the ground, the faster the lighting energy consumption decreases. This is because, when the window position is higher, the indoor natural lighting intensity is improved, thus the energy consumption of indoor lighting is reduced.

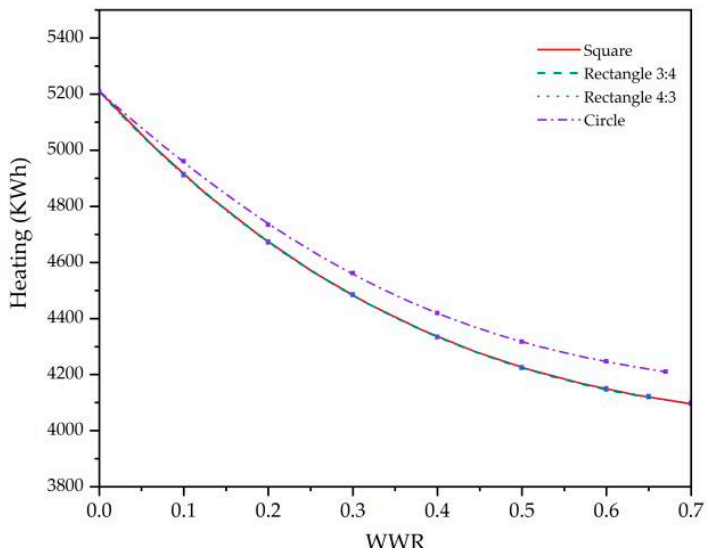

(a)

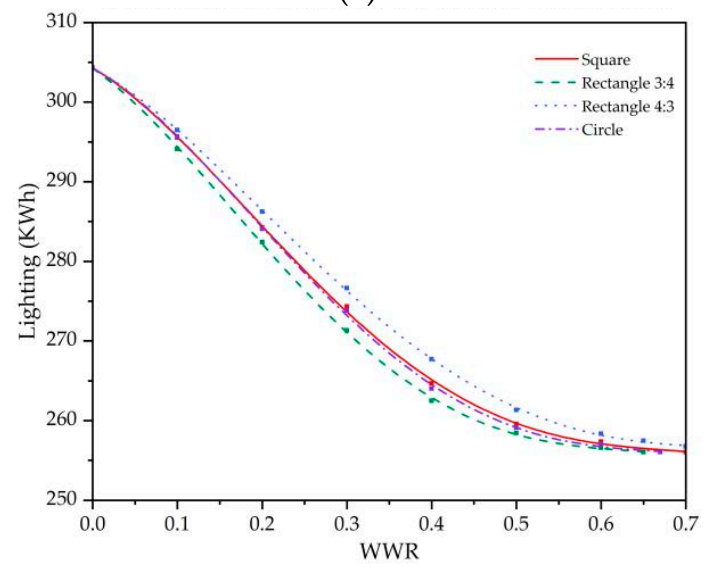

(c)

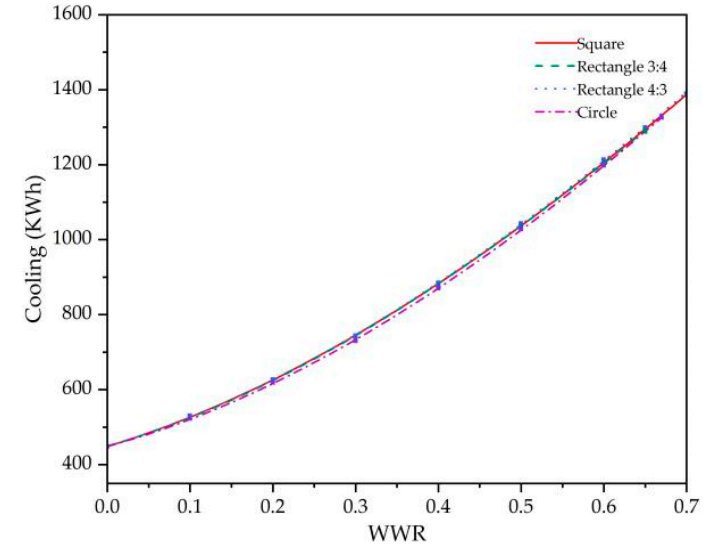

(b)

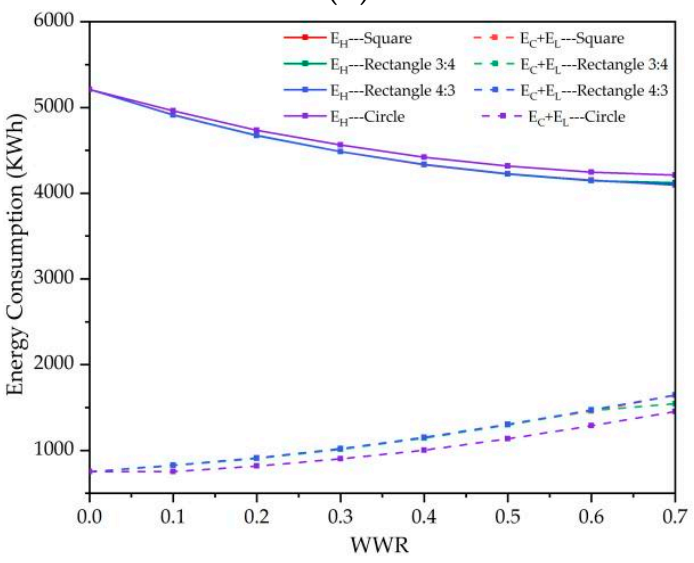

(d)

Figure 6. The relationships between the WWR and energy consumption of different window shapes: (a) WWR and $E_{H}$; (b) WWR and $E_{C} ;(\mathbf{c}) W W R$ and $E_{\mathrm{L}}$; and (d) WWR and $E_{\mathrm{H}}$ (using coal) and $\mathrm{E}_{\mathrm{C}}+\mathrm{E}_{\mathrm{L}}$ (using electricity).

In general, the shape and position of windows have specific impacts on each subtype of energy consumption of prefabricated residential buildings. These two design elements mainly have relatively significant effects on the lighting energy consumption, while the window area has a more significant impact on every subtype of energy consumption. The lighting energy consumption under each working condition shows a downward trend with an increase in WWR. The lighting energy consumptions under different window conditions gradually approach each other with a rise in WWR. As the window area increases, more natural lighting can be obtained indoors, thereby reducing the lighting energy consumption. However, when the WWR is large enough, indoor lighting is sufficient under the different working conditions, thus the influences of the shape and location factors on indoor lighting are weakened. 


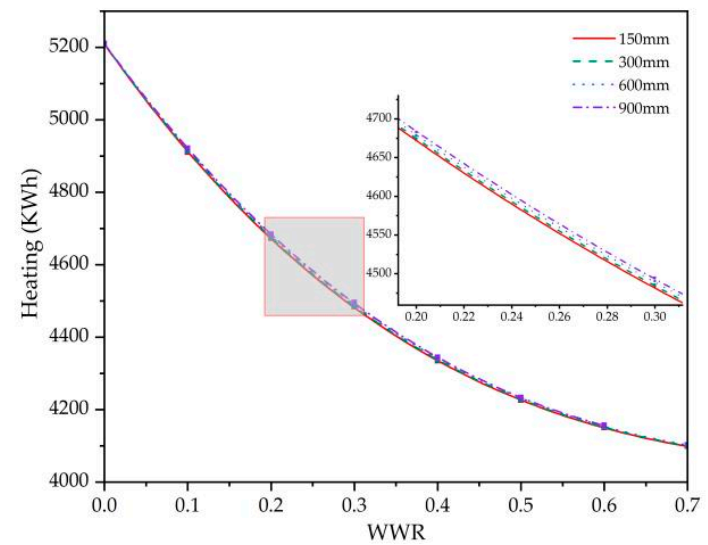

(a)

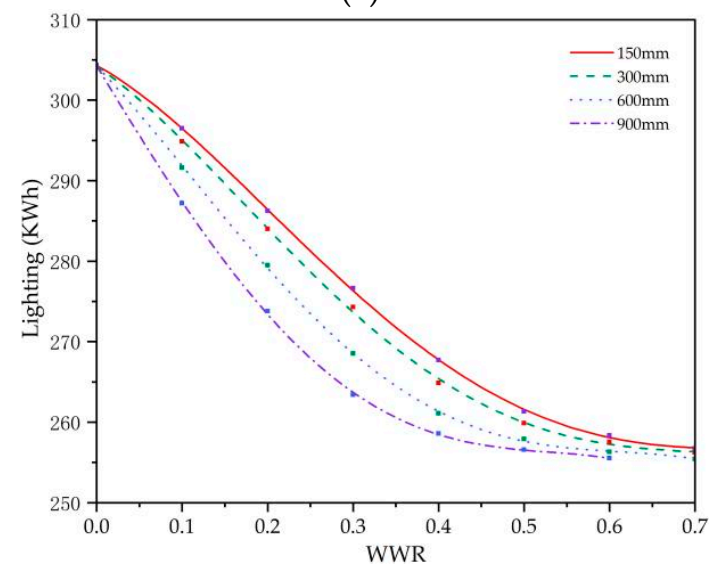

(c)

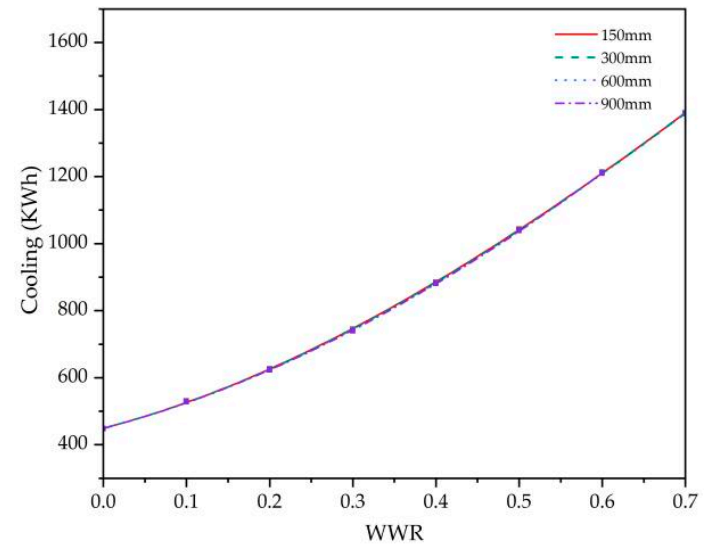

(b)

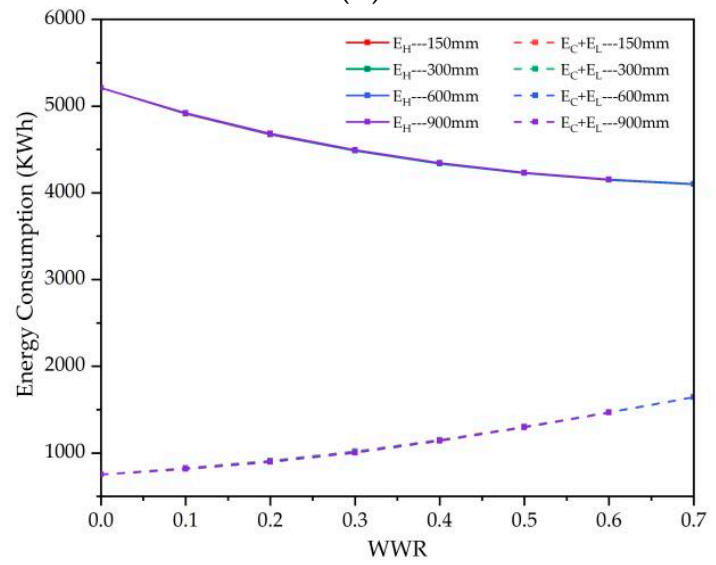

(d)

Figure 7. The relationships between the WWR and energy consumption with different window positions: (a) WWR and $E_{H}$; (b) WWR and $E_{C}$; (c) WWR and $E_{L}$; and (d) WWR and $E_{H}$ (using coal) and $E_{C}+E_{L}$ (using electricity).

\subsection{Influence of Window Design Elements on Optimal WWR}

In order to find the answer to the question about the influence of window position and shape on the optimal WWR, the function curves under different conditions were plotted in the coordinate system for sensitivity analysis. As shown in Figure 8, after calculation and data processing of the eight working conditions, eight function curves were obtained for each objective function corresponding to the eight optimal WWR values. The eight optimal WWR values are very close. The function image near the optimal WWR value is partially enlarged to enable comparison of the value of WWR under the different conditions. These partially enlarged images are attached to the main graphs.

It can be concluded from Figures 8 and 9 that the optimal WWR values for working conditions 1-8 under an energy-saving goal orientation are relatively close, all around 0.38 . The optimal WWR for circular windows is the lowest, about 0.37 . Therefore, the shape and position of windows under an energy-saving goal orientation have small influences on the optimal WWR. As can be seen from Figure 9, the optimal WWR values under different working conditions with a low-carbon goal are all about 0.15. The optimal WWR for circular windows with a low-carbon goal is the lowest, around 0.13 . With a low-carbon goal, the optimal WWR values for condition 2, condition 7 , and condition 8 are the highest, around 0.15 . 


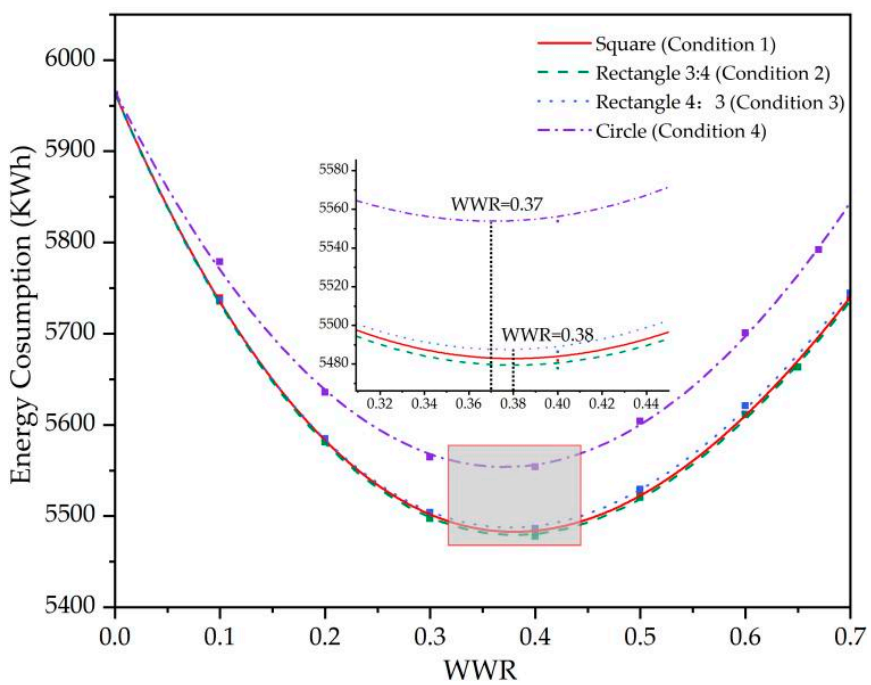

(a)

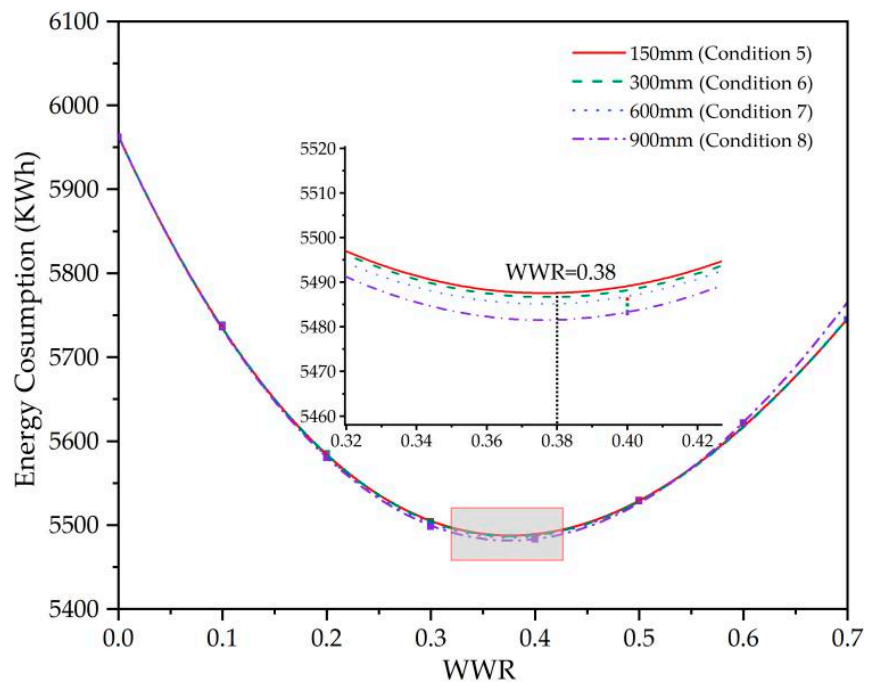

(b)

Figure 8. The optimal WWR values with energy consumption in different conditions: (a) different window shapes and (b) different window positions.

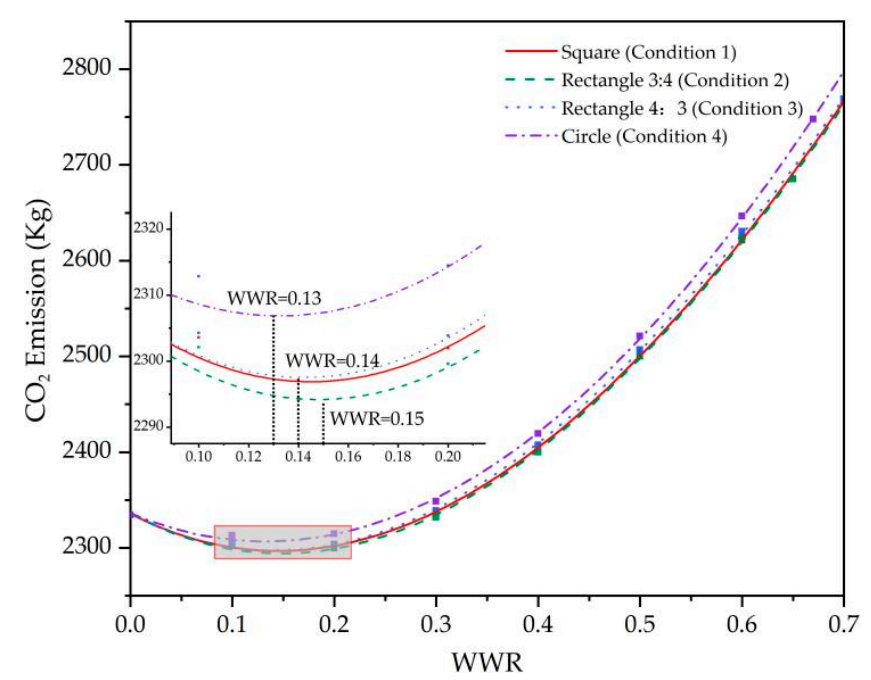

(a)

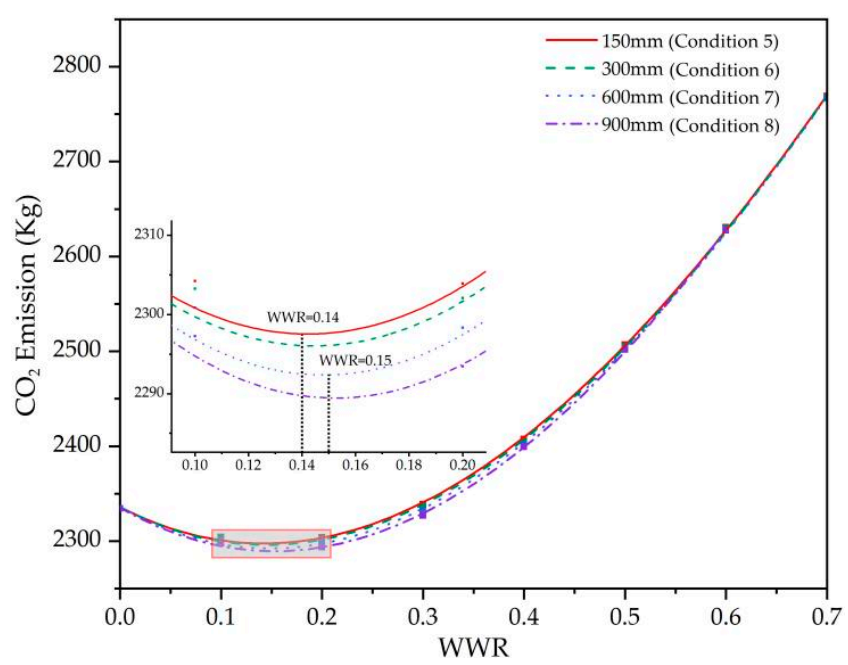

(b)

Figure 9. The optimal WWR values with a $\mathrm{CO}_{2}$ emission reduction target in different conditions: (a) different window shapes and (b) different window positions.

When analyzing the influence of the window design elements on the optimal WWR, the influences of the window shape and position design elements on energy consumption and $\mathrm{CO}_{2}$ emission can be investigated by transverse comparison when the WWR remains unchanged. As shown in Figure 8a, circular windows are the most unfavorable to energy saving, while rectangular windows with an aspect ratio of 3:4 are the most favorable to energy saving. As shown in Figure 8b, when the WWR is within the range 0.2-0.5, the higher the window from the ground, the more beneficial it is for energy saving. As can be seen from Figure 9a, the circular window is the most unfavorable for carbon reduction, while the rectangular window with an aspect ratio of 3:4 is the most favorable for carbon reduction. As shown in Figure 9b, when the WWR is in the range 0-0.5, the window with a height of $900 \mathrm{~mm}$ from the ground is the most beneficial for emission reduction. 


\subsection{Optimal WWR under Different Goal Orientations}

Window design methods should be different under the different goal orientations. In order to clarify the differences between low-carbon window design and energy-saving window design, it is necessary to compare and analyze the impacts of these different goal orientations on the optimal WWR. The curves for energy consumption and $\mathrm{CO}_{2}$ emissions changing with WWR under various conditions were plotted in a coordinate system.

The coordinate system contains two Y-axes, one representing the annual total energy consumption and the other representing the yearly $\mathrm{CO}_{2}$ emissions. It can be seen from Figure 10 that, when the WWR is the same, the energy consumption and $\mathrm{CO}_{2}$ emissions of the different window shapes are in the same order from low to high: the 3:4 rectangular window, the square window, the 4:3 rectangular window, and the circular window. In addition, it can be concluded from the figure that circular windows are more disadvantageous to energy-saving design compared with the other window shapes. Under the low-carbon goal orientation, the gap between circular windows and the other window shapes is smaller.

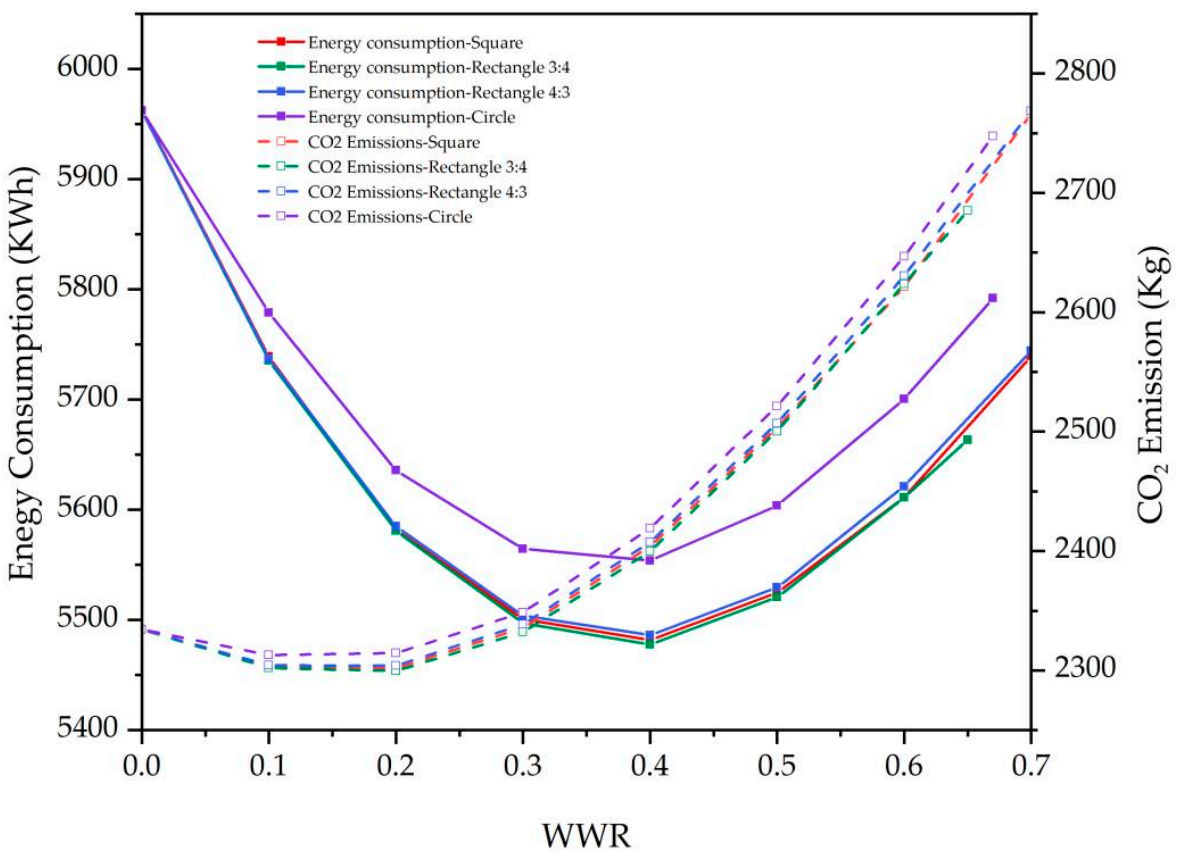

Figure 10. Comparison of changing trends of energy consumption and $\mathrm{CO}_{2}$ emissions with different window shapes.

As shown in Figure 11, under a low-carbon goal orientation and around the optimal WWR value, the higher windows have lower $\mathrm{CO}_{2}$ emissions. However, under an energysaving goal orientation, there is almost no difference in energy consumption between windows of different heights around the optimal WWR value. This indicates that window height is more critical for low-carbon design around the optimal WWR value than for energy-saving design.

It can be seen from a comparison between Figures 10 and 11 that the optimal WWR value obtained under a low-carbon goal orientation is smaller than that obtained under an energy-saving goal orientation. The value of the first optimal WWR is around 0.15, while that of the second is around 0.4. When the WWR value is between 0.2 and 0.4 , although energy consumption is still declining, the value of $\mathrm{CO}_{2}$ emissions begins to rise. The reason is the same as in the sensitivity analysis of subtype energy consumption shown in Figure 6d in Section 4.1; that is, the decreasing rate of heating energy consumption is gradually slowing down, while the increasing rate of the sum of lighting and cooling energy consumption is speeding up. As described in Section 3.2, when taking low carbon 
as an objective function, the subtype energy consumption needs to be multiplied by a $\mathrm{CO}_{2}$ emission coefficient to calculate $\mathrm{CO}_{2}$ emissions. The heating consumes coal, while the other two subtypes consume electricity. The $\mathrm{CO}_{2}$ emission coefficient of electricity is greater than that of coal. Therefore, after multiplying the $\mathrm{CO}_{2}$ emission coefficient, the value of $\mathrm{CO}_{2}$ emissions generated by an increase in electricity consumption will increase faster and quickly offset the reduction in $\mathrm{CO}_{2}$ emissions owing to the decrease in heating energy consumption, and thus make the inflection point of the function curve appear earlier. Therefore, with low carbon as the objective function, the value of the optimal WWR will be lower.

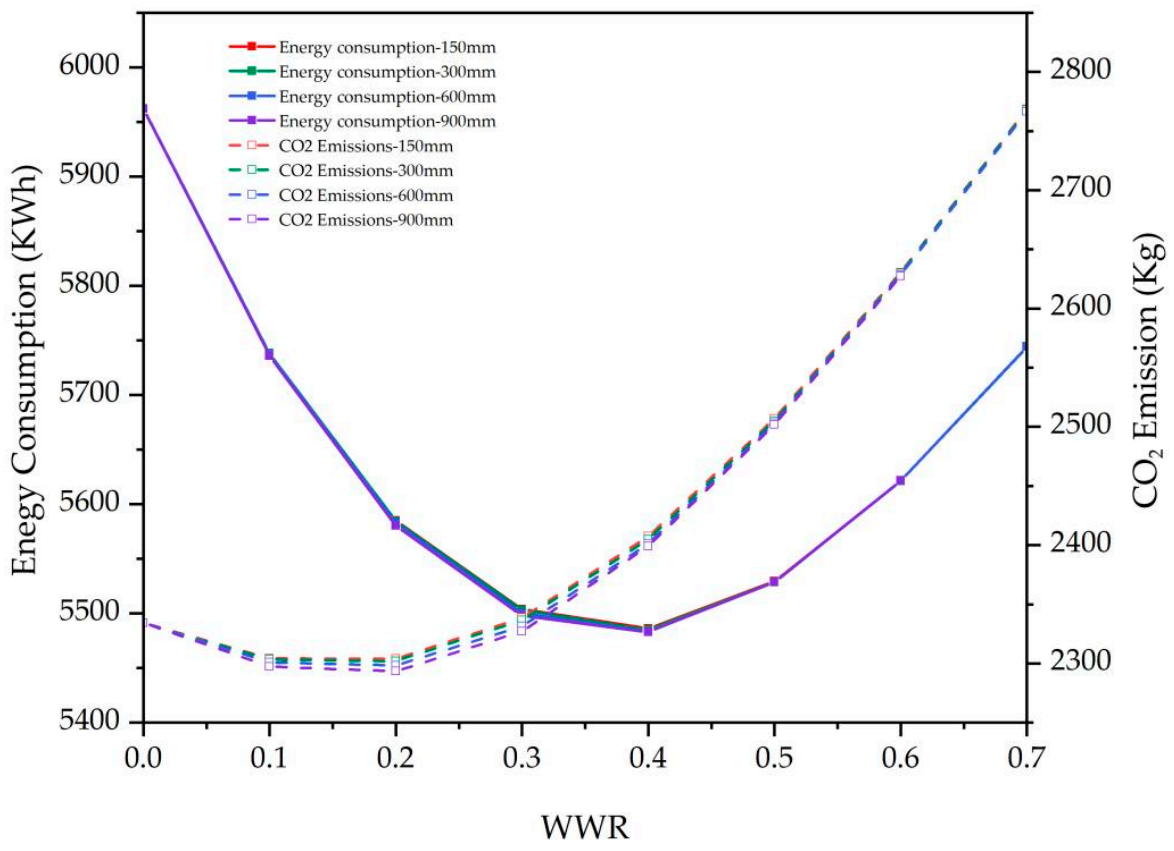

Figure 11. Comparison of changing trends of energy consumption and $\mathrm{CO}_{2}$ emissions with different window positions.

It can be seen from Figures 10 and 11 that energy consumption and $\mathrm{CO}_{2}$ emissions have the same variation trends with WWR under the different conditions, both showing downward trends at first and then upward trends. In the rising stage, the growth rates of energy consumption and $\mathrm{CO}_{2}$ emissions are gradually accelerating, indicating that a continuous increase in window area is not beneficial to either carbon reduction or energy saving when the WWR is large.

On the whole, although $\mathrm{CO}_{2}$ emissions are closely related to building energy consumption, the two are not the same. There are similarities and differences between low-carbon design and energy-saving design. Moreover, the overall trends of the objective function changes with WWR are the same. The difference is that the optimal WWR is different under the two different goal orientations. The value of the optimal WWR is lower when the objective function of prefabricated residential buildings is $\mathrm{CO}_{2}$ reduction. This shows that the window area of prefabricated residential buildings needs to be smaller when the goal is to reduce $\mathrm{CO}_{2}$ emissions. In addition, the window design elements have different effects on the different objective functions under the two different goal orientations. For example, around the optimal WWR value, window location factors significantly impact the low-carbon design more than the energy-saving design.

\subsection{Window Design Advice for Prefabricated Houses}

The influences of the window design elements on subtype energy consumption and the optimal WWR were analyzed above. The impacts of the two goal orientations on the optimal WWR were compared and analyzed. Analyzing the research results can 
help provide low-carbon design advice for prefabricated residential windows from the perspective of window design elements including window area, shape, and position.

The design advice for the window area is as follows. Firstly, the value of the WWR should be around 0.15 because, under a low-carbon goal orientation, the optimal WWR value is about 0.15 and the $\mathrm{CO}_{2}$ emissions are low within the range 0.1-0.2. Secondly, designers should be careful in making decisions to increase window area when the values of the WWR exceed the optimal WWR value because, the more the value of the WWR exceeds the optimal WWR, the faster $\mathrm{CO}_{2}$ emissions increase with an increase in WWR.

The design advice for window shape and position is as follows. Firstly, when changing window shape, designers should adjust the window area simultaneously to ensure that the value of the optimal WWR remains unchanged. This study has found that the window shape and position almost do not affect the optimal WWR. When architects adjust window shapes, the window area often changes. Therefore, the window area should be adjusted to around the optimal WWR to be most beneficial for building emission reduction. Secondly, circular windows should be avoided as far as possible when designing window shapes for prefabricated residential buildings. The reason for putting forward this advice is the $\mathrm{CO}_{2}$ emissions of circular windows are higher than those of other window shapes when the windows have the same area. However, when a window is designed to be round from an esthetic point of view, $\mathrm{CO}_{2}$ emissions can be reduced by reducing the circular window area. Thirdly, vertical strip-shaped rectangular windows should be preferentially used in prefabricated residential buildings. In this paper, with the same window area, a rectangular window with an aspect ratio of 3:4 has lower $\mathrm{CO}_{2}$ emissions than a rectangular window with an aspect ratio of 4:3. Therefore, it is suggested to use a vertical strip-shaped rectangular window to reduce $\mathrm{CO}_{2}$ emissions. Fourthly, when the window height from the ground is within the range $0-900 \mathrm{~mm}$ and the WWR is within $0-0.5$, the height of the window from the ground should be increased as far as possible to reduce the $\mathrm{CO}_{2}$ emissions of the building because, within this range, a higher window position is more beneficial for reducing $\mathrm{CO}_{2}$ emissions. After the WWR exceeds 0.5, window height will no longer affect $\mathrm{CO}_{2}$ emissions.

In addition, different design methods under the different goal orientations can be summarized by comparing the differences between window low-carbon design and window energy-saving design. First of all, the most energy-efficient window is not necessarily the most advantageous for reducing $\mathrm{CO}_{2}$ emissions. In a low-carbon design, the optimal WWR value should be reduced based on the optimal WWR obtained in relation to energy-saving design because the optimal WWR under a low-carbon goal orientation is lower than under an energy-saving goal orientation. Secondly, in a low-carbon window design, architects should pay more attention to the height of windows from the ground because this has a more significant impact on low-carbon design than on energy-saving design.

To analyze each factor's potential to reduce $\mathrm{CO}_{2}$ emissions, the most favorable working condition and the most unfavorable working condition for reducing $\mathrm{CO}_{2}$ emissions are selected in each group of simulations. As explained in Section 3.4.2, the corresponding $\mathrm{CO}_{2}$ emissions are expressed as Emin and Emax, and the carbon reduction potential $=($ Emax - Emin $) /$ Emax. By comparison, changing WWR has the greatest emission reduction potential of about $13 \%$. The second greatest is changing the shape element, with a potential of $0.5 \%$. The least is changing the position element, whose potential is $0.3 \%$. Therefore, in the design of prefabricated residential building windows, if the optimization options are limited, the priority should be to consider control of the WWR, that is, to keep it near the optimal WWR. Secondly, architects should ensure the shapes and positions of windows are optimized. On the whole, the position and shape of windows should be considered together in order to reduce $\mathrm{CO}_{2}$ emissions. For example, if increasing the height of the window cannot reduce $\mathrm{CO}_{2}$ emissions when the WWR exceeds 0.5 , optimizing the shapes and areas of prefabricated residential building windows is an excellent way to reduce $\mathrm{CO}_{2}$ emissions further. 


\section{Conclusions}

Architects using low-carbon and energy-saving design methods to design buildings can significantly help save energy and reduce $\mathrm{CO}_{2}$ emissions. This paper selected a representative prefabricated residential building with a plane size of $6 \mathrm{~m} \times 8.1 \mathrm{~m}$ and a floor height of $2.9 \mathrm{~m}$ as a basic model for simulation. Two groups of experiments were conducted according to the shape and height from the ground of the window. DB was used to simulate different building conditions to obtain data on energy consumption and $\mathrm{CO}_{2}$ emissions. The conclusions of this paper are as follows.

First of all, the results of this study indicate that different goal orientations can influence the value of the optimal WWR. The most energy-efficient windows are not necessarily the most conducive to reducing $\mathrm{CO}_{2}$ emissions. The optimal WWR under a low-carbon goal orientation is lower than that under an energy-saving goal orientation. In addition, window shape has a relatively small effect on the value of the optimal WWR. The findings of this study suggest that architects need to control WWR to keep it close to the optimal WWR when adjusting window shape. The circular window is the most unfavorable to energy conservation and $\mathrm{CO}_{2}$ emission reduction for buildings. The rectangular window with an aspect ratio of 3:4 is found to be the most favorable for reducing the $\mathrm{CO}_{2}$ emissions of buildings in this paper. From the perspective of carbon reduction, this may suggest choosing a window with a small aspect ratio. Furthermore, this research has shown that the window height from the ground has a greater impact on $\mathrm{CO}_{2}$ emissions than on building energy consumption. The results of this study indicate that, in the vicinity of the optimal WWR value, a higher window is more favorable for reducing $\mathrm{CO}_{2}$ emissions. When the WWR is greater than 0.5 , the influencing factor of window height will not impact $\mathrm{CO}_{2}$ emissions.

At present, the requirement for window design in the residential building energysaving code is oriented toward energy saving, which has significance for low-carbon building design, but also has limitations. It is necessary to formulate a targeted design strategy to guide the low-carbon design of buildings. This paper has discussed the influence of facade window design elements of prefabricated residential buildings on $\mathrm{CO}_{2}$ emissions and has put forward design advice that has contributions to architects' design of lowcarbon facades. This has great importance in promoting the low-carbon development of prefabricated residential buildings. However, there are some limitations of the research. There are many parameters that can affect the results of the optimal WWR. The variables in this article only include the architectural design elements of windows. In the future, further research can be carried out on the influence of climate parameters, lighting parameters, and indoor thermal comfort parameters on the optimal WWR.

Author Contributions: Conceptualization, S.L. and Y.C.; methodology, S.L., Y.C. and C.L.; software, S.L.; validation, Y.C., N.B., C.L. and M.B.L.; formal analysis, S.L.; investigation, S.L.; resources, N.B., C.L. and M.B.L.; data curation, S.L.; writing-original draft preparation, S.L.; writing-review and editing, Y.C., C.L., N.B. and M.B.L.; visualization, S.L.; supervision, Y.C. and C.L.; project administration, S.L.; funding acquisition, S.L. and Y.C. All authors have read and agreed to the published version of the manuscript.

Funding: This research was funded by Department of Science and Technology of Shandong Province, grant number 2017GSF22108. The first author is grateful to the China Scholarship Council (CSC) for a scholarship (No. 201908370239).

Data Availability Statement: Not applicable.

Conflicts of Interest: The authors declare no conflict of interest. 


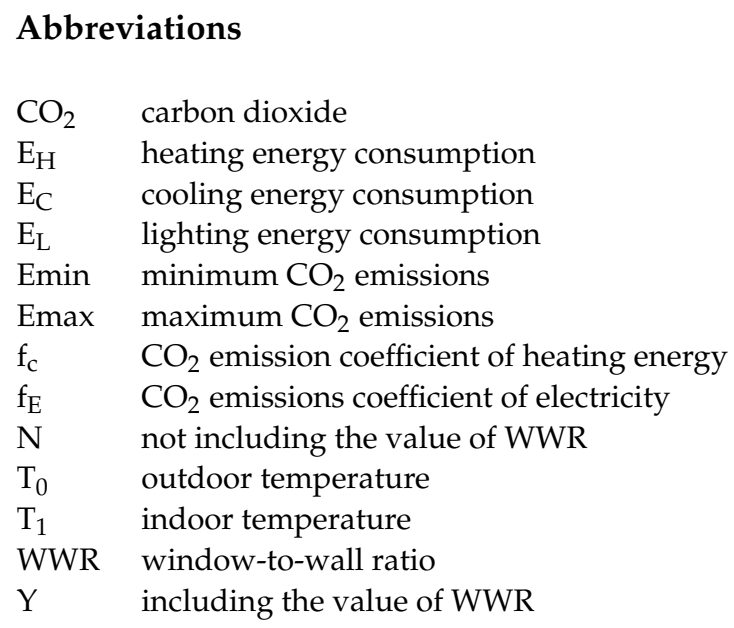

\section{Appendix A}

Table A1. Thermal parameters of wall structure.

\begin{tabular}{cccccccc}
\hline Property & Unit & $\begin{array}{c}\text { Autoclaved } \\
\text { Lightweight } \\
\text { Concrete }\end{array}$ & $\begin{array}{c}\text { Adhesive } \\
\text { Mortar }\end{array}$ & $\begin{array}{c}\text { XPS } \\
\text { Insulation } \\
\text { Board }\end{array}$ & $\begin{array}{c}\text { Protective } \\
\text { Layer of } \\
\text { Insulation } \\
\text { Slurry }\end{array}$ & $\begin{array}{c}\text { Leveling } \\
\text { Blanket of } \\
\text { Insulation } \\
\text { Slurry }\end{array}$ & $\begin{array}{c}\text { Anti-Crack } \\
\text { Mortar }\end{array}$ \\
\hline Thickness & $\mathrm{m}$ & 250 & 5 & 80 & 35 & 15 & 3 \\
\hline Dry density & $\mathrm{kg} / \mathrm{m}^{3}$ & $\leq 525$ & $\leq 1800$ & $18 \sim 22$ & $250 \sim 400$ & $250 \sim 400$ & 0.085 \\
\hline $\begin{array}{c}\text { Conductivity } \\
\text { coefficient }\end{array}$ & $\mathrm{W} / \mathrm{m} \mathrm{K}$ & 0.140 & 0.930 & 0.030 & 0.085 & 1.25 & 1.25 \\
\hline $\begin{array}{c}\text { Correction } \\
\text { factor } \alpha\end{array}$ & 1.15 & 1.00 & 1.05 & 0.930 & 1.00 \\
\hline $\begin{array}{c}\text { Thermal } \\
\text { resistance }\end{array}$ & $\mathrm{m}^{2} \cdot \mathrm{K} / \mathrm{W}$ & 0.932 & 0.005 & 1.212 & 0.329 & 0.141 \\
\hline
\end{tabular}

Table A2. Window optics and thermal performance parameters.

\begin{tabular}{cc}
\hline Property & $\begin{array}{c}\mathbf{6 ~ m m ~ M e d i u m ~ L i g h t - T r a n s m i t t a n c e ~ L o w - E ~ G l a s s ~ + ~ 1 2 ~ m m ~} \\
\text { Argon + 6 mm Transparent Glass }\end{array}$ \\
\hline Visible light transmittance & 0.623 \\
\hline Total solar transmittance & 0.45 \\
\hline Heat transfer coefficient & $1.481\left(\mathrm{~W} / \mathrm{m}^{2} \cdot \mathrm{K}\right)$ \\
\hline Radiance of coated glass hemisphere & 0.08 \\
\hline
\end{tabular}

Table A3. The structure and thermal parameters of the other parts of the building model.

\begin{tabular}{cccc}
\hline Structure & Material and Structure Thickness & Thermal Resistance & Heat Transfer Coefficient \\
\hline Roof & $\begin{array}{c}120 \text { reinforced concrete slab }+5 \text { adhesive } \\
\text { mortar }+ \text { XPS } 80+35 \text { protective layer of } \\
\text { insulation slurry }\end{array}$ & 2.414 & 0.283 \\
\hline Interior wall & 200 autoclaved aerated concrete & 2.81 & 0.58 \\
\hline Ground & $\begin{array}{c}40 \text { fine aggregate concrete }+20 \text { XPS }+120 \\
\text { reinforced concrete floor }+55 \text { rock wool }\end{array}$ & 2.123 & 0.44 \\
\hline
\end{tabular}




\section{References}

1. Sara, B.; Daniel, A.; Maria, G.G.; Antonio, M.R. Building façade retrofit with solar passive technologies: A literature review. Energies 2021, 14, 1774

2. Cui, Y.; Li, S.; Liu, C.; Sun, N. Creation and diversified applications of plane module libraries for prefabricated houses based on BIM. Sustainability 2020, 12, 453. [CrossRef]

3. Judkoff, R.; Neymark, J. International Energy Agency Building Energy Simulation Test (BESTEST) and Diagnostic Method; National Renewable Energy Lab: Denver, CO, USA, 1995.

4. Hu, X.; Liu, C. Total factor productivity measurement with carbon reduction. Eng. Constr. Archit. Manag. 2017, 24, 575-592. [CrossRef]

5. Moncef, K.; Mohammad, A. Role of energy efficiency and distributed renewable energy in designing carbon neutral residential buildings and communities: Case study of Saudi Arabia. Energy Build. 2021, 250, 111309.

6. Alsehail, A.; Almhafdy, A. The effectiveness of window design factors on the thermal performance: A REVIEW. Environ. Behav. Proc. J. 2020, 5, 165-173. [CrossRef]

7. Farzaneh, M.M.S.; Ali, S.; Mohammad, D.S.; Hoseyn, S.; Benedetto, N. The road to developing economically feasible plans for green, comfortable and energy efficient buildings. Energies 2021, 14, 636.

8. Farzaneh, M.M.S.; Ali, S.; Mohammad, D.S.; Hoseyn, S.; Benedetto, N. Acquiring the foremost window allocation strategy to achieve the best trade-off among energy, environmental, and comfort criteria in a building. Energies 2021, 14, 3962.

9. Jakob, C.; Bahram, M.; Jan, A.; Fredrik, K. Effects on energy demand in an office building considering location, orientation, façade design and internal heat gains-A parametric study. Energies 2020, 13, 6170.

10. Yeom, S.; Kim, H.; Hong, T.; Lee, M. Determining the optimal window size of office buildings considering the workers' task performance and the building's energy consumption. Build. Environ. 2020, 177, 106872. [CrossRef]

11. Troup, L.; Phillips, R.; Eckelman, M.J.; Fannon, D. Effect of window-to-wall ratio on measured energy consumption in US office buildings. Energy Build. 2019, 203, 109434. [CrossRef]

12. Zhang, L.; Liu, B.; Du, J.; Liu, C.; Wang, S. $\mathrm{CO}_{2}$ emission linkage analysis in global construction sectors: Alarming trends from 1995 to 2009 and possible repercussions. J. Clean. Prod. 2019, 221, 863-877. [CrossRef]

13. Fan, F.; Niraj, K.; Kristen, C.; Zheng, O.N. A critical review of fenestration/window system design methods for high performance buildings. Energy Build. 2021, 248, 111184.

14. Kaasalainen, T.; Mäkinen, A.; Lehtinen, T.; Moisio, M.; Vinha, J. Architectural window design and energy efficiency: Impacts on heating, cooling and lighting needs in Finnish climates. J. Build. Eng. 2020, 27, 100996. [CrossRef]

15. Zuzana, G. Pastophorium in the church of St. Catherine in Handlova in the context of the morphology of gothic pastophoria of Slovakia. Civ. Environ. Eng. 2021, 17, 1-8.

16. Nußholz, J.L.K.; Rasmussen, F.N.; Milios, L. Circular building materials: Carbon saving potential and the role of business model innovation and public policy. Resour. Conserv. Recycl. 2019, 141, 308-316. [CrossRef]

17. Christoph, S.; David, S.; Regine, O. How window ventilation behaviour affects the heat resilience in multi-residential buildings. Build. Environ. 2021, 202, 107987.

18. An, Y.; Xia, T.; You, R.; Lai, D.; Liu, J.; Chen, C. A reinforcement learning approach for control of window behavior to reduce indoor PM2.5 concentrations in naturally ventilated buildings. Build. Environ. 2021, 200, 10797. [CrossRef]

19. Mahtab, S.; Mohsen, F.; Mehdi, K.; Haniyeh, S. Energy and daylight optimization of shading devices, window size, and orientation for educational spaces in Tehran, Iran. J. Archit. Eng. 2021, 27, 04021011.

20. Wen, L.; Hiyama, K.; Koganei, M. A method for creating maps of recommended window-to-wall ratios to assign appropriate default values in design performance modeling: A case study of a typical office building in Japan. Energy Build. 2017, 145, 304-317. [CrossRef]

21. Lee, E.S.; Tavil, A. Energy and visual comfort performance of electrochromic windows with overhangs. Build. Environ. 2006, 42, 2439-2449. [CrossRef]

22. Susorova, I.; Tabibzadeh, M.; Rahman, A.; Clack, H.L.; Elnimeiri, M. The effect of geometry factors on fenestration energy performance and energy savings in office buildings. Energy Build. 2013, 57, 6-13. [CrossRef]

23. Yong, S.-G.; Kim, J.-H.; Gim, Y.; Kim, J.; Cho, J.; Hong, H.; Baik, Y.-J.; Koo, J. Impacts of building envelope design factors upon energy loads and their optimization in US standard climate zones using experimental design. Energy Build. 2017, 141, 1-15. [CrossRef]

24. Jaber, S.; Ajib, S. Thermal and economic windows design for different climate zones. Energy Build. 2011, 43, 3208-3215. [CrossRef]

25. Ihm, P.; Park, L.; Krarti, M.; Seo, D. Impact of window selection on the energy performance of residential buildings in South Korea. Energy Policy 2012, 44, 1-9. [CrossRef]

26. Hassan, M.A.; Guirguis, N.M.; Shaalan, M.R.; El-Shazly, K.M. Investigation of effects of window combinations on ventilation characteristics for thermal comfort in buildings. Desalination 2007, 209, 251-260. [CrossRef]

27. Wang, L.; Hien, W.N. The impacts of ventilation strategies and facade on indoor thermal environment for naturally ventilated residential buildings in Singapore. Build. Environ. 2006, 42, 4006-4015.

28. Aldawoud, A. Windows design for maximum cross-ventilation in buildings. Adv. Build. Energy Res. 2017, 11, 67-86. [CrossRef]

29. Wang, L.; Nyuk, H.W.; Li, S. Facade design optimization for naturally ventilated residential buildings in Singapore. Energy Build. 2006, 39, 954-961. [CrossRef] 
30. Zhai, Y.; Wang, Y.; Huang, Y.; Meng, X. A multi-objective optimization methodology for window design considering energy consumption, thermal environment and visual performance. Renew. Energy 2019, 134, 1190-1199. [CrossRef]

31. Goia, F.; Haase, M.; Perino, M. Optimizing the configuration of a façade module for office buildings by means of integrated thermal and lighting simulations in a total energy perspective. Appl. Energy 2013, 108, 515-527. [CrossRef]

32. Acosta, I.; Campano, M.Á.; Molina, J.F. Window design in architecture: Analysis of energy savings for lighting and visual comfort in residential spaces. Appl. Energy 2016, 168, 493-506. [CrossRef]

33. Goia, F. Search for the optimal window-to-wall ratio in office buildings in different European climates and the implications on total energy saving potential. Sol. Energy 2016, 132, 467-492. [CrossRef]

34. Baranova, D.; Sovetnikov, D.; Semashkina, D.; Borodinecs, A. Correlation of energy efficiency and thermal comfort depending on the ventilation strategy. Procedia Eng. 2017, 205, 503-510. [CrossRef]

35. Alghoul, S.K.; Rijabo, H.G.; Mashena, M.E. Energy consumption in buildings: A correlation for the influence of window to wall ratio and window orientation in Tripoli, Libya. J. Build. Eng. 2017, 11, 82-86. [CrossRef]

36. Yi, Y.K. Building facade multi-objective optimization for daylight and aesthetical perception. Build. Environ. 2019, 156, 178-190. [CrossRef]

37. Ali, H.; Esmaeil, S.S.; Reza, G.M. Effects of Different Window Configurations on Energy Consumption in Building: Optimization and Economic Analysis. J. Build. Eng. 2020, 35, 102099.

38. Moreno, Á.; Chemisana, D.; Vaillon, R.; Riverola, A.; Solans, A. Energy and luminous performance investigation of an OPV/ETFE glazing element for building integration. Energies 2019, 12, 1870. [CrossRef]

39. Shetabivash, H. Investigation of opening position and shape on the natural cross ventilation. Energy Build. 2015, 93, 1-15. [CrossRef]

40. Gao, C.F.; Lee, W.L. Evaluating the influence of openings configuration on natural ventilation performance of residential units in Hong Kong. Build. Environ. 2010, 46, 961-969. [CrossRef]

41. Hugo, H. Building Physics—Heat, Air and Moisture:Fundamentals and Engineering Methods with Examples and Exercises; Ernst \& Sohn Verlag für Architektur und Technische Wissenschaften GmbH \& Co. KG: Berlin, Germany, 2017; p. 2012.

42. Lupíšek, A.; Vaculíková, M.; ManL'ík, Š.; Hodková, J.; RůžiL'ka, J. Design strategies for low embodied carbon and low embodied energy buildings: Principles and examples. Energy Procedia 2015, 83, 147-156. [CrossRef]

43. Liu, Y.-F.; Luo, S.-S.; Wang, H. Research on a complete set of technologies for assembled residential buildings with steel-structure based on house type modularization and component standardization. IOP Conf. Ser. Earth Environ. Sci. 2021, $719,022063$. [CrossRef]

44. Li, J.; Lu, S.; Wang, W.; Huang, J.; Chen, X.; Wang, J.; Jesus, A.D. Design and climate-responsiveness performance evaluation of an integrated envelope for modular prefabricated buildings. Adv. Mater. Sci. Eng. 2018, 2018, 14. [CrossRef]

45. Ching, F.D.K. Architecture: Form, Space, and Order; Wiley: Hoboken, NJ, USA, 2012.

46. Moghtadernejad, S.; Chouinard, L.E.; Mirza, M.S. Design strategies using multi-criteria decision-making tools to enhance the performance of building façades. J. Build. Eng. 2020, 30, 101274. [CrossRef]

47. KuangSheng, L.; XiaoFeng, Z.; ChiaHsing, H.; ShinKu, L. The application of silica-based aerogel board on the fire resistance and thermal insulation performance enhancement of existing external wall system retrofit. Energies 2021, 14, 4518.

48. Karolis, B.; Jurga, K.; Arūnas, B.; Juozas, R.; Valdas, P. The changes in thermal transmittance of window insulating glass units depending on outdoor temperatures in cold climate countries. Energies 2021, 14, 1694.

49. Maestre, I.R.; Blázquez, J.L.F.; Gallero, F.J.G.; Baladés, J.D.M. Effect of sky discretization for shading device calculation on building energy performance simulations. Energies 2020, 13, 1381. [CrossRef]

50. Liu, X. Architecture Physics, 2nd ed.; Chen, H., Wang, Y., Eds.; Building Industry Press: Beijing, China, 2000; Volume 2, pp. 191-219. (In Chinese)

51. DesignBuilder 6.1.0.6. Available online: https:// designbuilder.co.uk/download (accessed on 10 August 2021). 